\title{
Composition of Brazil Nut (Bertholletia excels HBK), Its Beverage and By-Products: A Healthy Food and Potential Source of Ingredients
}

\author{
Wilson V. Vasquez-Rojas ${ }^{1,2} \mathbb{D}$, Diana Martín ${ }^{2} \mathbb{D}$, Beatriz Miralles ${ }^{3}\left(\mathbb{D}\right.$, Isidra Recio $^{3}$, Tiziana Fornari $^{2}$ \\ and M. Pilar Cano ${ }^{1, * \mathbb{D}}$ \\ 1 Department of Biotechnology and Microbiology of Foods, Institute of Food Science Research, \\ 28049 Madrid, Spain; ing.valeriovasquez@gmail.com \\ 2 Department of Production and Characterization of Novel Foods, Institute of Food Science Research, \\ 28049 Madrid, Spain; diana.martin@uam.es (D.M.); tiziana.fornari@uam.es (T.F.) \\ 3 Department of Bioactivity and Food Analysis, Institute of Food Science Research, 28049 Madrid, Spain; \\ beatriz.miralles@csic.es (B.M.); i.recio@csic.es (I.R.) \\ * Correspondence: mpilar.cano@csic.es; Tel.: +34-910017937
}

Citation: Vasquez-Rojas, W.V.; Martín, D.; Miralles, B.; Recio, I.; Fornari, T.; Cano, M.P. Composition of Brazil Nut (Bertholletia excels HBK), Its Beverage and By-Products: A Healthy Food and Potential Source of Ingredients. Foods 2021, 10, 3007. https: / / doi.org/10.3390/ foods 10123007

Academic Editors: Rosanna Di Paola, Roberta Fusco, Rosalba Siracusa and Ramona D'Amico

Received: 8 November 2021

Accepted: 26 November 2021

Published: 4 December 2021

Publisher's Note: MDPI stays neutral with regard to jurisdictional claims in published maps and institutional affiliations.

Copyright: (c) 2021 by the authors Licensee MDPI, Basel, Switzerland. This article is an open access article distributed under the terms and conditions of the Creative Commons Attribution (CC BY) license (https:// creativecommons.org/licenses/by/ $4.0 /)$.

\begin{abstract}
The consumption of plant-based beverages is a growing trend and, consequently, the search for alternative plant sources, the improvement of beverage quality and the use of their byproducts, acquire great interest. Thus, the purpose of this work was to characterize the composition (nutrients, phytochemicals and antioxidant activity) of the Brazil nut (BN), its whole beverage (WBM), water-soluble beverage (BM-S), and its by-products of the beverage production: cake, sediment fraction (BM-D), and fat fraction (BM-F). In this study, advanced methodologies for the analysis of the components were employed to assess HPLC-ESI-QTOF (phenolic compounds), GC (fatty acids), and MALDI-TOF/TOF (proteins and peptides). The production of WBM was based on a hot water extraction process, and the production of BM-S includes an additional centrifugation step. The BN showed an interesting nutritional quality and outstanding content of unsaturated fatty acids. The investigation found the following in the composition of the BN: phenolic compounds (mainly flavan-3-ols as Catechin (and glycosides or derivatives), Epicatechin (and glycosides or derivatives), Quercetin and Myricetin-3-O-rhamnoside, hydroxybenzoic acids as Gallic acid (and derivatives), 4-hydroxybenzoic acid, ellagic acid, Vanillic acid, p-Coumaric acid and Ferulic acid, bioactive minor lipid components ( $\beta$-Sitosterol, $\gamma$-Tocopherol, $\alpha$-Tocopherol and squalene), and a high level of selenium. In beverages, WBM had a higher lipid content than BM-S, a factor that influenced the energy characteristics and the content of bioactive minor lipid components. The level of phenolic compounds and selenium were outstanding in both beverages. Hydrothermal processing can promote some lipolysis, with an increase in free fatty acids and monoglycerides content. In by-products, the BM-F stood out due to its bioactive minor lipid components, the BM-D showed a highlight in protein and mineral contents, and the cake retained important nutrients and phytochemicals from the BN. In general, the BN and its beverages are healthy foods, and its by-products could be used to obtain healthy ingredients with appreciable biological activities (such as antioxidant activity).
\end{abstract}

Keywords: Brazil nut; cake (by-product); Brazil nut beverage; phenolic compounds; fatty acids; proteins; tocopherols; squalene; antioxidant capacity; minerals; selenium

\section{Introduction}

The Brazil nut (Bertholletia excelsa HBK), also known as the Amazon nut, is a plant of the family Lecythidaceae, native to the Amazon rainforest and concentrated along the Amazon basin, marketed mainly by the countries of Bolivia, Brazil, and Peru. The socioeconomic and environmental importance of the Brazil nut lies in its production system as a non- 
timber forest product coming mainly from natural areas (not crops) and the generation of income in local populations [1].

In the nutritional and health field, in the last decade, there has been an increased interest in nuts and their positive effects on human health, associating nut consumption with the reduced risk of various degenerative diseases [2]. Studies on Brazil nut consumption, and its effects on health, report interesting benefits, such as the reduction in risk factors for cardiovascular disease, cancer prevention, and improved cognitive functions. These benefits can be attributed to the biological properties, nutrients, and phytochemical constituents that this nut possesses, such as its majority level of unsaturated fatty acids, selenoamino acids, dietary fiber, minerals, phenolic compounds, tocopherols, and phytosterols [3].

Considering these potential benefits of the Brazil nut, its added value has been encouraged with a focus on the development of health-promoting foods, such a Brazil nut beverage popularly known as "Brazil nut milk", belonging to a sector of alternative beverages to dairy milk. In recent years, this sector has shown an increasing in demand, driven by several reasons such as the "negative" effects of cow's milk in certain consumer groups, e.g., protein allergy, lactose intolerance, the content of saturated fat, and the presence of cholesterol; as well as the preference of people with a healthy diet and lifestyle, those conscious of the environment, and concerns for animal welfare [4]. Although plant-based milk usually has added sugar and is low in protein, its appreciable content of unsaturated fatty acids, essential minerals, phenolic compounds, and other bioactive compounds makes it a healthy food alternative. However, the market for plant-based milk is limited to a few sources (mainly soy and almond), and further study is needed to focus on their bioactive compounds, as well as their effect on processing and the remaining by-products [5]. The scarce reports on Brazil nut beverages are mainly related to standardization (raw material/water ratio, homogenization temperature, formulation, drying, among others) and quality (sensory, nutritional, physicochemical, and microbiological) [6-9], with an absence of studies related to its bioactive compounds and their biological properties, as well as the potential use of its by-products generated in their processing.

Therefore, the present work seeks to characterize the nutritional attributes, the phytochemicals, and the antioxidant properties of Brazil nuts, its beverage, and by-products, in order to evaluate their potential as healthy food alternatives and healthy ingredients. In the context of sustainable production, this study supports the investigation of the functional beverages of the Brazil nut and the use of its generated by-products.

\section{Materials and Methods}

\subsection{Plant Material}

Brazil nuts, dry seed, and shelled (without woody tegument), were purchased from a local market in Madrid (Spain) in April 2019. The vacuum packaged Brazil nuts were stored in a refrigerated room with an average temperature of $4{ }^{\circ} \mathrm{C}$ until analysis and processing. All processing and analyses were carried out over a period of four months.

\subsection{Solvents, Reagents, and Standards}

Methanol (99.8\% LC-MS) was purchased from VWR International (Barcelona, Spain). Ultra-pure water (Mili-Q) was obtained from a Millipak ${ }^{\circledR}$ Express 40 system (Merck Millipore, Darmstadt, Germany). The reagents acetone, sodium carbonate, $\mathrm{n}$-hexane, formic acid, and chloroform were purchased from VWR (Barcelona, Spain). Potassium peroxydisulfate $(\mathrm{K} 2 \mathrm{~S} 2 \mathrm{O} 8)$, potassium phosphate $\left(\mathrm{KH}_{2} \mathrm{PO}_{4}\right)$, sodium phosphate $\left(\mathrm{NaH}_{2} \mathrm{PO}_{4}\right)$, Trolox (6-hydroxy-2,5,7,8-tetramethylchroman-2-carboxylic acid), fluorescein, N, O-bis (trimethylsilyl) trifluoroacetamide (BSTFA), Folin-Ciocalteu reagent, 2,2-diphenyl-1picrylhydrazyl (DPPH), 2,20-azino-bis(3-ethylbenzthiazoline-6-sulfonic acid) (ABTS), 2,20azobis (2-methylpropionamidine) dihydrochloride (AAPH), standards for GC analysis (DL- $\alpha$-tocopherol, squalene, oleic acid, CI-stearoyl-RAC Glycerol and $\beta$-sitosterol), and for HPLC analysis (catechin, epicatechin, vanillic acid, protocatechuic acid, quercetin, vanillin, gallic acid and hydroxybenzoic acid) were purchased from Sigma-Aldrich (Mis- 
souri, MO, USA). For protein analysis: Tris- $\mathrm{HCl}$ and Trizma base (Sigma-Aldrich), SDS (Merck, Darmstadt, Germany), glycerol (Panreac Química SAU, Castellar del Vallès, Spain), $\beta$-mercaptoethanol (Sigma-Aldrich, Madrid, Spain), bromophenol blue (Merck, Darmstadt, Germany), bis-trispolyacrylamide gels (Criterion XT, Bio-Rad, Hercules, CA, USA), XT MES running buffer 20x (Bio-Rad Laboratories S.A, Madrid, Spain), and Coomassie Blue (Instant blue, Expedeon, UK).

\subsection{Production of Brazil Nut Beverage}

The production of whole Brazil nut beverage (WBM) was obtained using the method reported by Felberg et al. as a reference [6]. A centrifugation stage was added for partial fractionation and as a strategy to reduce the level of fat and obtain the water-soluble beverage (BM-S), as shown in Figure 1. Briefly, the Brazil nuts were ground to reduce their size (particle size $<5 \mathrm{~mm}$ ), then they were homogenized with water at $75{ }^{\circ} \mathrm{C}$ using the ratio 7:1 (water: raw material, $v / w$ ) for five minutes until the mixture reached a homogeneous consistency via a high-speed homogenizer at $7500 \mathrm{rpm}$ (OMNI Macro-ES Programmable Homogenizer, OMNI International, Kennesaw, GA 30144, United States). Then, this solution was immediately filtered with stainless mesh $(\leq 2 \mathrm{~mm})$ to obtain a hot aqueous extract or WBM and cake by-product. For the fractionation of WBM, the liquid was maintained at $5{ }^{\circ} \mathrm{C}$ for $1 \mathrm{~h}$ and then it was centrifuged at $15,000 \times g$ at $5{ }^{\circ} \mathrm{C}$ for $15 \mathrm{~min}$, producing its separation in three phases: the fat fraction (BM-F) from the upper phase, the water-soluble fraction (BM-S) from the intermediate phase, and the sediment fraction (BM-D) from lower phase. Each fraction was manually collected. Finally, all the fractions were frozen with liquid nitrogen, freeze-dried, packed in vacuum bags, and kept at $-20{ }^{\circ} \mathrm{C}$ until analysis.

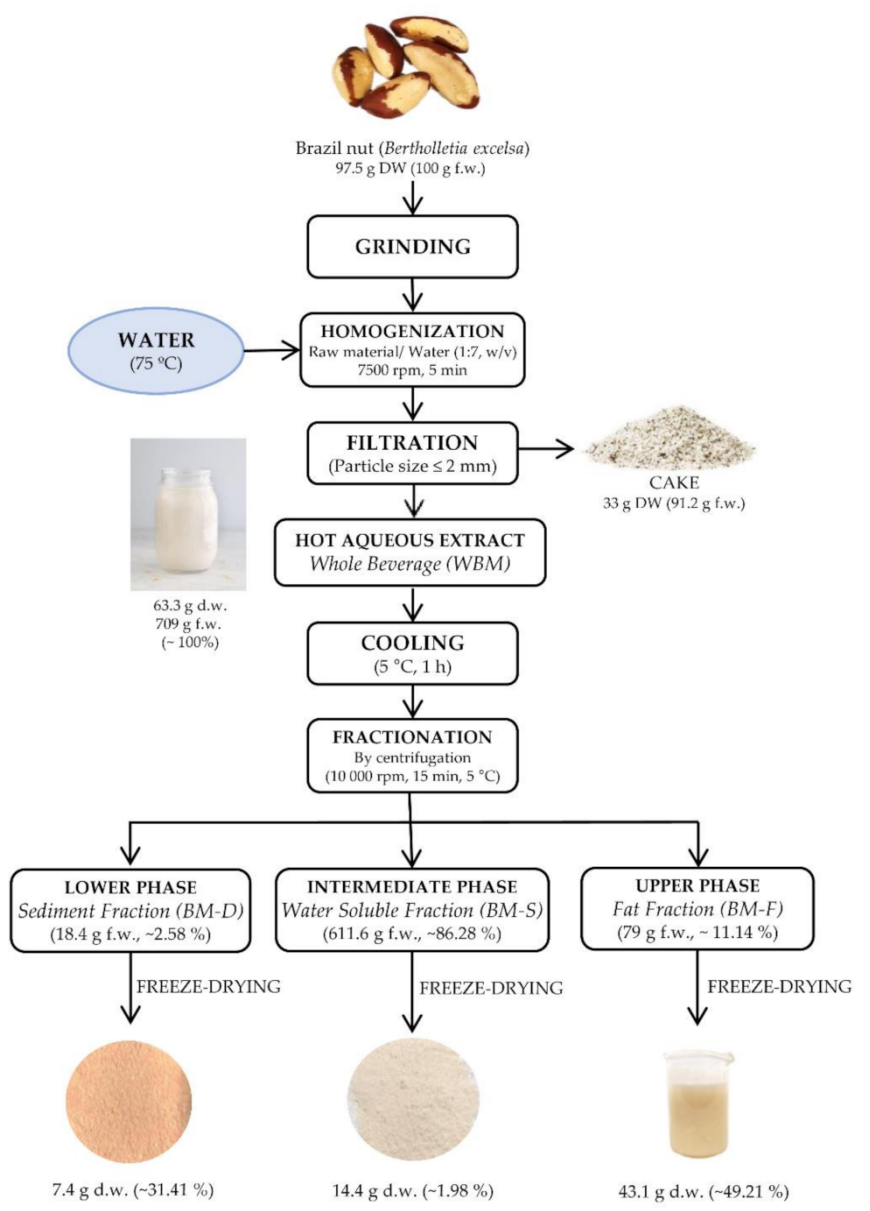

Figure 1. Flow chart of the Brazil nut milk production and process by-products. 


\subsection{Methods of Analysis}

\subsubsection{Physicochemical Analysis}

The centesimal composition of the samples was determined using the following methods: ash, moisture, and dry matter were analyzed following AOAC standardized methods [10]; the total protein content was determined by the elemental chemical analysis of nitrogen (conversion factor: 6.25); the total lipid content was determined by the Folch method [11]; the total carbohydrate was calculated by the difference. Regarding the physicochemical properties, the $\mathrm{pH}$ was determined by direct reading on a digital potentiometer (Metrohm $827 \mathrm{pH}$ Meter, Metrohm, Herisau, Switzerland), the total acidity concentration in the samples was calculated via potentiometric titration [10], and the ${ }^{\circ}$ Brix (soluble sugars) was measured using a digital refractometer (PR-32 $\alpha$, ATAGO ${ }^{\mathrm{TM}}$, Tokyo, Japan).

\subsubsection{Phenolic Compounds}

Extraction

Phenolic compounds were extracted using the method reported by John and Shahidi, with some modifications [12]. Each sample was previously defatted with hexane (1:5 w/v) and homogenized for $5 \mathrm{~min}$, in triplicate. The obtained solution was then filtered through filter paper. The solid residue (defatted) was dried at room temperature for $12 \mathrm{~h}$ in the dark and covered to avoid oxidation. It was then extracted with acetone, in a ratio of 1:15 $(w / v)$, homogenized at $7500 \mathrm{rpm}$ for $4 \mathrm{~min}$ in an ultra-speed homogenizer (OMNI Macro-ES Programmable Homogenizer, OMNI International, Kennesaw, GA, USA), and later submitted to reflux in a water bath at $60{ }^{\circ} \mathrm{C}$ for $40 \mathrm{~min}$ with magnetic stirring. The resulting slurry was centrifuged at $15,000 \times g$ for $10 \mathrm{~min}$, and the supernatant was collected. The sediment was re-extracted under the same conditions, then the supernatants were combined, and the solvent was removed by vacuum at $40{ }^{\circ} \mathrm{C}$. The extract containing the phenolic compounds was stored at $-20^{\circ} \mathrm{C}$ until its use for the analysis of the total phenolics and antioxidant activity. For the HPLC analysis of the individual phenolic compounds, the extract was freeze-dried (Lyobeta-15, Azbil Telstar, S.L., Terrasa, Spain) for $72 \mathrm{~h}$ and the samples were stored at $-20^{\circ} \mathrm{C}$ until analysis.

\section{Total phenolics Content (TPC)}

The total phenolics in the samples (phenolic extracts) were analyzed spectrophotometrically with Folin-Ciocalteu reagent according to the method of Cano et al. [13], with some modifications. In a 96-microwell plate, the reactants were placed in the following order: $20 \mu \mathrm{L}$ samples (extracts, standard, and blank) were reacted with $100 \mu \mathrm{L}$ Folin-Ciocalteu reagent $(10 \%, v / v)$ and then alkalized with $80 \mu \mathrm{L}$ of $\mathrm{Na}_{2} \mathrm{CO}_{3} 7.5 \%(w / v)$. The mixture was stirred and kept in darkness for one hour at $20^{\circ} \mathrm{C}$. The reading was taken spectrophotometrically at $756 \mathrm{~nm}$ (Varioskan Flash, Thermo Fisher Scientific, Waltham, MA, USA). Gallic acid was used as the reference standard to elaborate the calibration curve with concentrations in the range of $50-500 \mu \mathrm{g} / \mathrm{mL}$. The results were expressed as $\mathrm{mg}$ of gallic acid equivalents (GAE)/100 g dry weight (d.w.) or fresh weight (f.w.).

\section{Individual Phenolic Compounds}

Phenolic lyophilized extracts (BN, BM-S, and BM-D) were dissolved with methanol/water $(2: 1, v / v)$ and filtered with $0.45 \mu \mathrm{m}$ syringe filters before injection into HPLC UV/Vis. Chromatographic analyses were performed according to the protocol reported by GarcíaCayuela et al. [14], using a 1200 Series Agilent HPLC System (Agilent Technologies, Santa Clara, CA, USA) with a reverse phase C18 column (Zorbax SB-C18, $250 \times 4.6 \mathrm{~mm}, 5 \mu \mathrm{m}$; Agilent) maintained at $20^{\circ} \mathrm{C}$. Elution solvent A consisted of $1 \%$ formic acid $(v / v)$ in water, while solvent B was a mixture of methanol and formic acid $(1 \%, v / v)$. Separation was achieved using an initial solvent composition of $15 \%$ (B) during $15 \mathrm{~min}$, increased to $25 \%$ (B) within $10 \mathrm{~min}$, ramped to $50 \%$ (B) within $10 \mathrm{~min}$, increased to $75 \%$ (B) in $15 \mathrm{~min}$, and followed by a decreased period of $15 \%$ (B) in $5 \mathrm{~min}$ prior to isocratic re-equilibration at $15 \%$ (B) for $10 \mathrm{~min}$. The flow rate was fixed at $0.8 \mathrm{~mL} / \mathrm{min}$, and the injection volume was 
$20 \mu \mathrm{L}$. The UV-vis photodiode array detector was set at 3 wavelengths $(280,320,380 \mathrm{~nm})$ for monitoring different phenolic chemical families simultaneously.

The HPLC-DAD was coupled to a mass spectrometry detector (LCMS SQ 6120, Agilent, CA, USA) with an electrospray ionization (ESI) source operating in positive ion mode. The drying gas was nitrogen at $3 \mathrm{~L} / \mathrm{min}$ at $137.9 \mathrm{KPa}$. The nebulizer temperature was $300{ }^{\circ} \mathrm{C}$, and the capillary had $3500 \mathrm{~V}$ potential. The coliseum gas was helium, and the fragmentation amplitude was $70 \mathrm{~V}$. Spectra, recorded $m / z$ from 100-1000. Further mass spectrometry analyses were performed using maXis II LC-QTOF equipment (Bruker Daltonics, Bremen, Germany) with an ESI source and the same chromatographic conditions. The ESI-QTOF detector worked in positive ion mode and recorded spectra $\mathrm{m} / \mathrm{z}$ from 50-3000. The operation conditions were $300{ }^{\circ} \mathrm{C}$, capillary voltage $3500 \mathrm{~V}$, charging voltage $2000 \mathrm{~V}$, nebulizer $2.0 \mathrm{bar}$, and dry gas at $6 \mathrm{~L} / \mathrm{min}$. MS/MS analysis used the bbCID (broadband Collision-induced dissociation) method at $30 \mathrm{eV}$.

Phenolic compounds were identified according to their retention times, UV/Vis, and mass spectral data compared to those of commercial or purified standards. Quantitation of most phenolic compounds was determined using the calibration curves of the corresponding isolated standards. Quercetin glycosides were quantified by using the rutin calibration curve.

\subsubsection{Lipids and Other Minor Lipidic Compounds \\ Extraction}

The lipids in the samples were extracted using the method of Folch, Lees, and Sloane Stanley [11] as follows. Briefly, $1 \mathrm{~g}$ of sample was mixed with $20 \mathrm{~mL}$ of chloroform-methanol $(2: 1, v / v)$ to be homogenized in a T-25 Ultraturrax (IKA-Werke GmbH \& Co., KG, Staufen, Germany) at 11,000 rpm for $3 \mathrm{~min}$, followed by sonication by ultrasound bath for $3 \mathrm{~min}$ and then centrifuged at $1050 \times g$ for $10 \mathrm{~min}$. The supernatant was collected and stirred with $4 \mathrm{~mL}$ of distilled water by vortex and then centrifuged again at $1050 \times g$ for $10 \mathrm{~min}$. The bottom organic phase was collected and filtered with paper and dried with anhydrous sodium sulphate. The lipid solution obtained was dried on a rotary evaporator under a vacuum at $40{ }^{\circ} \mathrm{C}$ and kept at $-20^{\circ} \mathrm{C}$ until analysis.

Fatty Acids

The fatty acids (FA) profile of lipid samples was determined after the derivatization of fatty acid methyl esters (FAMEs). Briefly, $20 \mathrm{mg}$ of sample was mixed with $0.5 \mathrm{~mL}$ chloroform/methanol $(2: 1 ; v / v)$ and $1 \mathrm{~mL}$ of $0.1 \mathrm{M} \mathrm{NaOH}$ in methanol. This mixture was heated at $60^{\circ} \mathrm{C}$ for $30 \mathrm{~min}$, and then the reaction was stopped with the addition of $0.2 \mathrm{~mL}$ of distilled water. The FAMEs formed were extracted with the addition of $1 \mathrm{~mL}$ of hexane. After stirring, it was decanted, and the isolated upper phase was collected. Anhydrous sodium sulfate was added to the solution of FAMEs to eliminate aqueous traces for $30 \mathrm{~min}$. Finally, the hexane was removed under a nitrogen atmosphere.

The obtained FAMEs were dissolved in hexane to a concentration of $1 \mathrm{mg} / \mathrm{mL}$ for each sample and injected into the gas chromatograph Agilent 7890 A (Agilent Technologies, California, PA, USA) equipped with a split-splitless injector and an autosampler, a flame ionization detector, and a triple-axis mass spectrometer detector. FAMEs were separated using an HP-5MS column (30 m length, $0.25 \mathrm{~mm}$ internal diameter, and $0.25 \mu \mathrm{m}$ film thickness). Helium was used as a carrier gas at $2 \mathrm{~mL} / \mathrm{min}$. The injection temperature was $260^{\circ} \mathrm{C}$, splitless mode, $1 \mu \mathrm{L}$, and the mass spectrometer ion source and interface temperatures were 230 and $280^{\circ} \mathrm{C}$, respectively. The chromatographic analysis started at $50{ }^{\circ} \mathrm{C}$ and increased at a speed of $20^{\circ} \mathrm{C} / \mathrm{min}$ until it reached $210^{\circ} \mathrm{C}$, there it stayed for $18 \mathrm{~min}$, then it went up to $230^{\circ} \mathrm{C}$ and remained there for $13 \mathrm{~min}$. The running time was $40 \mathrm{~min}$. The mass spectra were obtained by electronic impact at $70 \mathrm{eV}$. The scan rate was 1.6 scans/s at a mass range of 30-700 amu. The identification of fatty acids was performed by the NIST MS Data library. The area under each FA peak in relation to the total area of all FA peaks was used for quantification and expressed as a percentage of FA. 
Minor Lipid Compounds: Free Fatty Acids, Monoglycerides, Tocopherols, Phytosterol, and Squalene

For the analysis of these minor compounds, the lipid extracts were derivatized using N, O-bis(trimethylsilyl)trifluoroacetamide (BSTFA). The procedure used was based on that of Herrera et al. [15]. Briefly, $5 \mathrm{mg}$ of the sample was mixed with $1 \mathrm{~mL}$ of the derivatizing agent and then submitted to $75{ }^{\circ} \mathrm{C}$ for $1 \mathrm{~h}$, shaking every $15 \mathrm{~min}$. Finally, it was injected into the previously described chromatography equipment, and the separation procedure was started at $50{ }^{\circ} \mathrm{C}$ and was held for $3 \mathrm{~min}$, increasing to $310^{\circ} \mathrm{C}$ at a rate of $15^{\circ} \mathrm{C} / \mathrm{min}$ and held for $25 \mathrm{~min}$. For quantification, calibration curves were obtained from the standards of $\alpha$-tocopherol, squalene, oleic acid, stearoyl-RAC glycerol, and $\beta$-sitosterol, which were also previously derivatized.

\subsubsection{Proteins}

\section{SDS-PAGE Analysis}

The electrophoresis assay was performed on Precast Criterion XT 4-12\% Bis-Tris gels using the Criterion cell (Bio-Rad, Hercules, CA, USA) as reported by Sanchón et al. [16]. The samples were dissolved at $0.8 \mathrm{mg}$ of protein $/ \mathrm{mL}$ in a buffer containing $0.05 \mathrm{M}$ Tris- $\mathrm{HCl}$, $\mathrm{pH} 6.8,8 \%(v / v)$ glycerol, $1.6 \%(w / v)$ SDS, $2 \%(v / v) \beta$-mercaptoethanol, and $0.002 \%(w / v)$ bromophenol blue. The concentration was calculated at $0.8 \mathrm{mg}$ protein $/ \mathrm{mL}$ buffer solution. Then, they were heated at $95^{\circ} \mathrm{C}$ for $4 \mathrm{~min}$, and $45 \mu \mathrm{L}$ was loaded onto the $4-12 \%$ Bis-Tris polyacrylamide gel as well as $15 \mu \mathrm{L}$ of the molecular weight marker (Precision Plus Protein unstained Standard (Bio-Rad, Bio-Rad, Hercules CA, USA). Electrophoretic separation was carried out using XT-MES as a running buffer (BioRad). After $5 \mathrm{~min}$ at 100, $150 \mathrm{~V}$ were applied. The gels were washed with Milli-Q water and were stained with Coomassie blue G-250. Images were taken with a Molecular Imager ${ }^{\circledR}$ VersaDoc $^{\text {TM }}$ MP 5000 system (Bio-Rad, Hercules, CA, USA) and processed with Quantity One ${ }^{\circledR} 1-\mathrm{D}$ analysis software (Bio-Rad Laboratories S.A, Madrid, Spain).

\section{Mass Spectrometry Analysis of Peptides}

To identify the proteins on the SDS-PAGE gels, bands were cut out from the gels and transferred to a microcentrifuge tube. Subsequently, in-gel reduction, alkylation, and tryptic digestion were carried out as previously reported by Miralles et al. [17]. An Autoflex speed MALDI-TOF/TOF (Bruker Daltonics, Bremen, Germany) instrument was used for mass spectra generation. The Mascot server (www.matrixscience.com, Matrix Science, London, UK) was used to carry out protein identification searches against a homemade database of Bertholletia excelsa and Pisum sativum proteins selected from the UniProt database (https:/ / www.uniprot.org/ (accessed on 22 May 2020)).

\subsubsection{Minerals}

\section{Selenium}

For the quantification of selenium (Se), the protocol proposed by López-Bellido et al. [18] was followed, with some modifications. Briefly, the dry samples (approximately $0.5 \mathrm{~g}$ ) were pretreated by acid digestion, using $\mathrm{HNO}_{3}$ in a microwave (UltraWAVE Milestone, Shelton, CT, USA). Then, the samples were diluted 1:2 $(w / v)$ with $1 \%$ nitric acid and analyzed by inductively coupled plasma mass spectrometry (ICP-MS model NexION 300 X, Perkin Elmer $^{\circledR}$, Waltham, MA, USA) under the following operating conditions: nebulizer quartz concentric, spray chamber PC3 Peltier Cooled Cyclonic, RF Power $1500 \mathrm{~W}$, nebulizer gas flow of $0.86 \mathrm{~L} / \mathrm{min}$, scanning mode in peak hopping, d.w.ell time of $50 \mathrm{~ms}, 20$ sweeps, 1 reading, 3 replicates, analytes ${ }^{78} \mathrm{Se}$ and ${ }^{80} \mathrm{Se}$, internal standard ${ }^{72} \mathrm{Ge}$, and reaction mode $\mathrm{CH} 4=0.70 \mathrm{~mL} / \mathrm{min}$ and $\mathrm{RPq}=0.55$. Calibration standards at $0.05,0.1,0.5,1,5,10$, and $50 \mu \mathrm{g} / \mathrm{L}$ were prepared from a $1000 \mathrm{mg} / \mathrm{L}$ stock solution of Se (SCP Science) in 1\% nitric acid. One internal standard (Ge at $30 \mu \mathrm{g} / \mathrm{L}$ ) was used to correct for signal drift. The results were expressed as $\mu \mathrm{g} / 100 \mathrm{~g}$ d.w. or f.w. 


\section{Other Minerals}

The analysis was performed by the high-resolution atomic absorption spectrometry (HR-CS AAS) method according to the procedure suggested by Nielsen [19], with certain modifications. First, the samples were digested: $1 \mathrm{~g}$ of the samples, with nitric acid and hydrogen peroxide (both of high purity), were added and submitted to a programmed temperature of $200^{\circ} \mathrm{C}$ using the microwave digestion system equipment (Ethos UP, Milestone Srl, Sorisole, Italy). The digested samples were diluted with $50 \mathrm{~mL}$ of distilled water. In the second stage, the HR- CS AAS was used (ContrAA 700, Analytik Jena AG, Jena, Germany). Air-acetylene flame was applied for all minerals except calcium (Ca) and phosphorus (F). The Ca required the more calorific acetylene nitrous oxide flame. $\mathrm{F}$ was determined using a graphite furnace. Each element was determined by the previous calibration of specific certified standards. The minerals obtained were expressed in $\mathrm{mg} / 100 \mathrm{~g}$ d.w. or f.w.

\subsubsection{Antioxidant Capacity \\ DPPH Assay}

The antioxidant capacity was determined by the DPPH (2,2-diphenyl-1-picrylhydrazyl) radical scavenging method according to the method of Abe et al. [20], with some modifications. In a 96-well microplate, the reaction was carried out as follows: a $50 \mu \mathrm{L}$ aliquot of the sample extract, previously diluted with methanolic solution $(70 \%)$, was mixed with $250 \mu \mathrm{L}$ of DPPH $(0.5 \mathrm{mM})$ and after $25 \mathrm{~min}$ in the dark, the absorbance was measured at $517 \mathrm{~nm}$ using spectrophotometric equipment (Varioskan Flash de Thermo Electron Corporation ${ }^{\circledR}$, Waltham, MA, USA) and analyzed with SkanIt Re for Varioskan 2.4.1 ${ }^{\circledR}$ software (Varioskan Flash de Thermo Electron Corporation ${ }^{\circledR}$, Waltham, MA, USA). The reference standard for obtaining the calibration curve consisted of a methanolic solution of Trolox (6-hydroxy-2,5,7,8-tetramethylchroman-2-carboxylic acid) at different concentrations $(100-800 \mu \mathrm{M} / \mathrm{mL})$. The antioxidant capacity was expressed as $\mu \mathrm{mol}$ Trolox equivalent (TE)/g d.w. or f.w.

\section{TEAC Assay}

The radicals ABTS+ were generated according to Koroleva et al. [21], with some modifications. ABTS and potassium peroxodisulfate (K2S2O8) were dissolved in water at final concentrations of 7 and $140 \mathrm{mM}$, respectively. The ABTS stock solution was obtained by mixing both reagents in a ratio of $17.6 \mu \mathrm{L} \mathrm{K2S2O8/mL} \mathrm{ABTS.} \mathrm{To} \mathrm{get} \mathrm{a} \mathrm{daily} \mathrm{solution}$ of radical ABTS, the stock solution was diluted with phosphate-buffered saline (PBS, $75 \mathrm{mM}, \mathrm{pH}$ 7.4), constituted by potassium phosphate (KH2PO4) and sodium phosphate (NaH2PO4), until an optical density of $0.70 \pm 0.02$ at $734 \mathrm{~nm}$. TE solutions $(10-100 \mu \mathrm{M})$ were used for calibration. The reaction was initiated by mixing $30 \mu \mathrm{L}$ of the sample extract, or standard, with $200 \mu \mathrm{L}$ of ABTS+, then left to stand $40 \mathrm{~min}$ and the absorbance was measured spectrophotometrically at $734 \mathrm{~nm}$. Values were calculated based on the linear regression equation between the TE concentration and the decrease in absorbance. Antioxidant capacity was expressed as $\mu \mathrm{mol} \mathrm{TE} / \mathrm{g}$ d.w. or f.w.

\section{ORAC Assay}

The oxygen radical antioxidant capacity (ORAC) was determined according to the method proposed by Gómez-Maqueo et al. [22], with some modifications. The extracted samples and TE were dissolved with phosphate-buffered saline (PBS) $75 \mathrm{mM}$ at pH 7.4. A TE curve was prepared using concentrations ranging from 10-45 mM. In a microwell plate, $20 \mathrm{~mL}$ of the sample extract, or standard, was added to each microwell, then $120 \mathrm{~mL}$ of $11.7 \mu \mathrm{M}$ fluorescein solution was added. The microplate was incubated at $37^{\circ} \mathrm{C}$ for $10 \mathrm{~min}$.

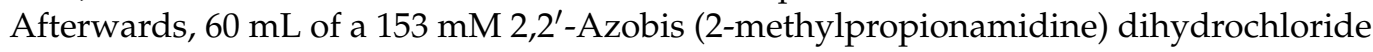
(AAPH) solution were added. In a 96-well microplate reader (Varioskan Flash de Thermo Electron Corporation ${ }^{\circledR}$, Waltham, MA, USA), plate lecture was registered every minute for $55 \mathrm{~min}$ at $37^{\circ} \mathrm{C}$ and with an excitation wave of $485 \mathrm{~nm}$ and emission wave of $530 \mathrm{~nm}$. The 
data analysis was performed by obtaining the area under the curve (AUC) and subtracting the blank. The results were expressed as $\mu \mathrm{mol} \mathrm{TE} / \mathrm{g}$ d.w. or f.w.

\subsubsection{Statistical Analysis}

The values are expressed as mean and standard deviation. The obtained results were evaluated with variance analysis (ANOVA), and differences between means were located using Tukey's test. The significant statistical differences were calculated at a $p<0.05$ level. The statistic software employed was IBM SPSS Statistic 20.

\section{Results and Discussion}

\subsection{Production of Brazil Nut Beverage}

Figure 1 show the production procedure reported in the Materials and Methods section, using a ratio of $\mathrm{BN} /$ water 1: $7(w / v)$. In this process, $100 \mathrm{~g}$ f.w. of $\mathrm{BN}$ with $700 \mathrm{~mL}$ of water, $709 \mathrm{~g}$ f.w. of WBM and $611.6 \mathrm{~g}$ f.w. of BM-S, were obtained. That is, to obtain WBM and BM-S beverage, 14.11 and $16.4 \%(w / v)$ of raw material were required, respectively. In commercial plant-based milks, the raw material content varies in the range of $2-15 \%$ (data from field survey, taken from the labels of the main brands of vegetal milk available in Madrid, Spain.) $(w / v)$, depending on the type of raw material, raw material/water ratio, technological processes, and the prefixed characteristics of the final product. In the literature regarding the production of Brazil nut beverages, the use of various BN/water ratios have been reported, as 1:2 (w/v) [9] and 1:7 (w/v) [6]. The latter ratio was used in our work due to the good yield of total solids at $77^{\circ} \mathrm{C}$ and the remarkable nutritional profile. A remarkable aspect of BM-S was a better appearance of stability than WBM since fat and sediment fraction was separated by centrifugation. It is true that this process would reduce the formation of sedimentation (particles with higher density), and cream formation (oily bodies of low density) during its storage, but does not affect the nutritional composition, as verified in the following sections.

Regarding the by-products in the process of BN milk production, the cake is the first residue from processing, with an amount of roughly $33 \mathrm{~g}$ d.w. from $100 \mathrm{~g}$ f.w. ( $97.5 \mathrm{~g}$ d.w.) produced from the initial raw material (BN). These results are similar to those reported $(36.14 \%, w / w$, d.w.) in a previous study using partially defatted BN to obtain the BN beverage [9], an important amount of food material for subsequent utilization. Furthermore, on a fresh weigh basis, BM-D and BM-F residues represent less than $14 \%(w / w)$ of the WBM, but on a dry basis they are very important and reach $31.4 \%(w / w)$ of BM-D and $49.2 \%(w / w)$ of BM-F, significative in large production volumes.

\subsection{Physicochemical Properties}

The centesimal composition of the Brazil nut, its beverages (BWM and BM-S), and by-products (cake, BM-D and BM-F), are shown in Table 1. The macronutrients of BN, in order of predominance, are the lipids (58.5/100 g f.w.), followed by carbohydrates (19.6/100 g f.w.), proteins (16/100 g f.w.), and ash (3.3/100 g f.w.). The high caloric power of $669.2 \mathrm{Kcal}$, mainly provided by lipid level, makes BN an energetic food with a valuable nutritional contribution.

In BN beverages, the total solids content of the WBM beverage was about $9 / 100 \mathrm{~g}$ f.w., a higher level than BM-S with around 2/100 $\mathrm{g}$ f.w., when the vegetable milk commercials can vary in a range of $3-23 \%(w / w)$ [5]. The nutrients that conform to the WBM were dominated by total lipids with 5.24/100 $\mathrm{g}$ f.w., followed by carbohydrates with 1.94/100 g f.w., proteins with $1.43 / 100 \mathrm{~g}$ f.w., ash with $0.33 / 100 \mathrm{~g}$ f.w., and an energy content of 60.6 $\mathrm{kcal} / 100 \mathrm{~g}$ f.w. These values are close to those obtained by Felberg et al. [6], who used a similar process. 
Table 1. Centesimal composition and physicochemical properties of the Brazil nut (Bertholletia excelsa HBK), its beverages, and by-products.

\begin{tabular}{|c|c|c|c|c|c|c|}
\hline \multirow{2}{*}{ Characteristic } & \multirow{2}{*}{$\frac{\text { Raw Material }}{\mathrm{BN}^{1}}$} & \multicolumn{2}{|c|}{ Beverages } & \multicolumn{3}{|c|}{ By-Products } \\
\hline & & WBM $*, 1$ & BM-S $^{1}$ & BM-D ${ }^{2}$ & BM-F $^{2}$ & Cake $^{2}$ \\
\hline Protein & 16.03 & 1.43 & 0.80 & 56.88 & 0.65 & 16.9 \\
\hline Lipid & 58.52 & 5.24 & 0.25 & 14.6 & 81.3 & 44.2 \\
\hline Carbohydrate & 19.61 & 1.94 & 0.83 & 16.65 & 16.29 & 35.45 \\
\hline Ashes & 3.35 & 0.33 & 0.10 & 11.87 & 1.76 & 3.5 \\
\hline Energy (Kcal) & 669.2 & 60.6 & 8.8 & 425.5 & 799.5 & 607.2 \\
\hline Total solids 1 & 97.51 & 8.93 & 1.98 & 31.41 & 49.21 & 36.17 \\
\hline Acidity $^{3}$ & 0.18 & 0.03 & 0.03 & 0.54 & - & 0.1 \\
\hline $\mathrm{pH}$ & 6.4 & 6.5 & 6.5 & 6.7 & - & 6.6 \\
\hline Soluble solid $\left({ }^{\circ}\right.$ Brix $)$ & 14.5 & 2.6 & 3.0 & 4.8 & - & 6.8 \\
\hline
\end{tabular}

Abb.: Brazil nut (BN), Whole beverage (WBM), Water soluble fraction (BM-S), Sediment fraction (BM-D). * Values of WBM were estimated from the fractions; ${ }^{1}$ Expressed as $\mathrm{g} / 100$ fresh weight (f.w.); ${ }^{2}$ Expressed as $\mathrm{g} / 100 \mathrm{~g}$ fry weight (d.w.); ${ }^{3}$ Expressed as g citric acid $/ 100 \mathrm{~g}$.

In the case of the BM-S beverage, it had a higher predominance of proteins ( $0.8 / 100 \mathrm{~g}$ f.w.) and carbohydrates $(0.83 / 100 \mathrm{~g}$ f.w.), and a minimum composition of lipids $(0.25 / 100 \mathrm{~g}$ f.w.), ash $(0.1 / 100 \mathrm{~g}$ f.w.), and a minimum energy content ( $8.8 \mathrm{kcal} / 100 \mathrm{~g}$ f.w.). In general, there was a reduction of macronutrients in BM-S compared to WBM (mainly in lipid content, which decreased up to roughly 20 times) due to the centrifugation process and separation of the BM-D and BM-F fractions. Commercial vegetable milks have a wide compositional variation: in protein from $0.1-3.3 \%(w / v)$, in lipids from $0.3-7.2 \%(w / v)$, in carbohydrates from $0-13.4 \%(w / v)$, and in energy content from $21-121 \mathrm{kcal} / 100 \mathrm{~mL}$ [23]. Therefore, WBM and BM-S are beverages comparable to commercial vegetable milk, but the WBM has a high energy input, as opposed to the BM-S.

Regarding the by-products, the cake had a notable nutritional composition of lipids (44.2/100 g d.w.), carbohydrates (35.45/100 g d.w.), proteins (16.85/100 g d.w.), and ash $(3.5 / 100 \mathrm{~g}$ d.w.). These values are consistent with those reported by Sartori et al. [9], who produced the beverage from partially defatted BN. In addition, regarding the byproducts obtained after centrifugation, the BM-D fraction showed an important content (about 57/100 g d.w.), probably due in part to the effect of the thermal denaturation of some proteins and the increased hydrophobicity [24]. This fact was observed in soy and almond milk when they were subjected to moderate heat treatments (around $60-80{ }^{\circ} \mathrm{C}$ ), showing lower precipitation and protein denaturation than those produced when they were treated at high temperatures (over $85^{\circ} \mathrm{C}$ ) $[25,26]$. In the case of the BM-F fraction, it had a predominance of lipid content (about 80/100 g d.w.), being related to the high-fat content coming from the raw material.

In the physicochemical characteristics (Table 1), the $\mathrm{pH} \sim 6.5$ of the Brazil nut and cake were consistent with the previously published studies [27]. The $\mathrm{pH}$ of WBM and BM-S were within the range ( $\mathrm{pH}: 5-8)$ of most vegetable milks [5]. The high level of acidity $(0.54 \mathrm{~g}$ citric acid/100 g) of the sediment (BM-D) could be influenced by amino acids due to their high protein content $(\sim 57 \%, w / w)$. Regarding the content of soluble solids, the BN has the highest value with $14.5^{\circ}$ Brix due to low moisture $(2.5 \%, w / w)$, and the WBM and BM-S have $\sim 3{ }^{\circ}$ Brix, due to dilution in water of BN processing. The by-products (BM-D and cake), in dry weight, have a low content of soluble solids that can be attributed to the effect of the hydrothermal process for obtaining the beverage and the consequent extraction of water-soluble substances for BN.

\subsection{Phenolic Compounds}

\subsubsection{Total Phenolic Content (TPC)}

The Folin-Ciocalteau method allowed the quantification of TPC present in the samples. Table 2 show these data. The TPC of BN was $108 \mathrm{mg}$ GAE/100 g d.w. $\quad(\sim 100.1 \mathrm{mg}$ GAE/100 g f.w.), this value was similar to a previous report [20] but differed from that 
obtained by John and Shahidi [12], who reported $519 \mathrm{mg}$ GAE/100 $\mathrm{g}$ f.w. This difference can be attributed to different factors inherent to the plant, industrial processes, and methods of extraction and analysis.

Table 2. Total phenolic content of the Brazil nut (Bertholletia excelsa HBK), its beverages (WBM and BM-S), and by-products (BM-D and cake), expressed in mg GAE/100 g.

\begin{tabular}{cccccc}
\hline \multirow{2}{*}{ Samples } & \multicolumn{4}{c}{ TPC } \\
\cline { 3 - 6 } & & \multicolumn{2}{c}{ Dry Weight } & \multicolumn{2}{c}{ Fresh Weight } \\
\hline \multirow{2}{*}{ Raw material } & BN & 108.0 & $\pm 3.9^{\mathrm{b}}$ & 105.3 & $\pm 3.8^{\mathrm{a}}$ \\
\multirow{2}{*}{ Beverages } & WBM & 79.5 & $\pm 1.5^{\mathrm{b}}$ & 7.1 & $\pm 0.1^{\mathrm{c}}$ \\
& BM-S & 314.0 & $\pm 5.2^{\mathrm{a}}$ & 6.2 & $\pm 0.1^{\mathrm{c}}$ \\
By-products & BM-D & 83.4 & $\pm 3.1^{\mathrm{b}}$ & 28.7 & $\pm 1.1^{\mathrm{b}}$ \\
& Cake & 49.2 & $\pm 2.7^{\mathrm{c}}$ & 17.8 & $\pm 1.0^{\mathrm{b}}$ \\
\hline
\end{tabular}

Data are expressed as means \pm SD $(n=3)$. Values with different superscript letters in the column are significantly different $(p<0.05) ;{ }^{*}$ Value of WBM was estimated from their fractions.

Regarding the Brazil nut beverages, the WBM and BM-S showed similar total phenol content, with 7.1 and $6.2 \mathrm{mg}$ GAE/100 g f.w., respectively. These were higher values than those reported for commercial vegetable milks, which ranged from $0.02-1.24 \mathrm{mg} / 100 \mathrm{~mL}$ [28]. However, some studies may show higher phenolic concentrations, such as almond milk with $71 \mathrm{mg} / 100 \mathrm{~g}$ f.w. [29].

When analyzing the TPC level on a dry basis, according to Table 2, the BM-S (314 mg GAE $/ 100 \mathrm{~g}$ d.w.) was significantly higher $(p \leq 0.05)$ than the rest of the samples $(<84 \mathrm{mg}$ GAE/100 g d.w.). According to the data of John and Shahidi [12], the phenolic extract of BN contained roughly $97 \%(w / w$, fresh weight) soluble phenolics and less than $5 \%(w / w$, fresh weight) bound phenolics, this would explain the higher TPC in the BM-S beverage.

Regarding the cake by-product, with $49.2 \mathrm{mg} \mathrm{GAE} / 100 \mathrm{~g}$ d.w., it has a TPC nearly to half of $\mathrm{BN}$, a reduction consistent with the high concentration of soluble polyphenols present in the BN transferred to the aqueous fraction (BM-S). There are no reports of TPC in cake from the BN beverage. However, Gomes et al. [30], in their study of phenolic extraction of cake (from defatting of the BN), obtained a TPC from 143-182 mg GAE/100 g. In the cake (by-product) of soybean milk, known as "okara", the total phenol content is recorded to be from 620-2913 mg GAE/100 g d.w. [31,32]. Therefore, at the level of total phenols, the cake from the BN beverage process is relatively low. As for the BM-D fraction, precipitated by-product, with $83.4 \mathrm{mg}$ GAE/100 g d.w., their total phenols would be to a greater extent conjugated (esterified) with amino acids and peptides (due to their high total protein content $\sim 57 \%$ in dry weight), decanted by factors such as higher molecular weight, lower aqueous solubility (as globulins and glutelins), and protein denaturation. The fat fraction (BM-F) was not analyzed for total phenol content due to its high-fat content (greater than $80 \%, w / w$, dry weight) and the antecedents regarding its minimum TPC level of $\mathrm{BN}$ oil, as $3.6 \mathrm{mg} \mathrm{GAE} / 100 \mathrm{~g}$ oil [33].

\subsubsection{Identification of Individual Soluble Phenolic Compounds}

After the extractions, in an aqueous solvent (70\% acetone), the soluble phenols of each sample were characterized. The profile of phenolic compounds of the Brazil nut, water-soluble fraction (BM-S), and sediment fraction (BM-D) was conducted by HPLCDAD (UV/Vis detection) and by HPLC- ESI-QTOF, analyzing retention times, UV spectra, mass spectral data compared to those of commercial and purified standards, and to reported data (Table 3). The UV-vis detection was simultaneously recorded at 280, 320, and $380 \mathrm{~nm}$, achieving the identification of 24 compounds: 4 organic acids, 10 phenolic acids, 9 flavonoids, and 1 phenolic aldehyde. The HPLC chromatogram at $280 \mathrm{~nm}$ (Figure 2) showed a better resolution of the peaks for the identification of the phenolic compounds present in the samples. Table 3 show the HPLC retention times, UV/Vis spectra, and MS 
spectral data of individual phenolics in the Brazil nut (Bertholletia excelsa), water-soluble fractions (BM-S), and sediment fraction (BM-D).

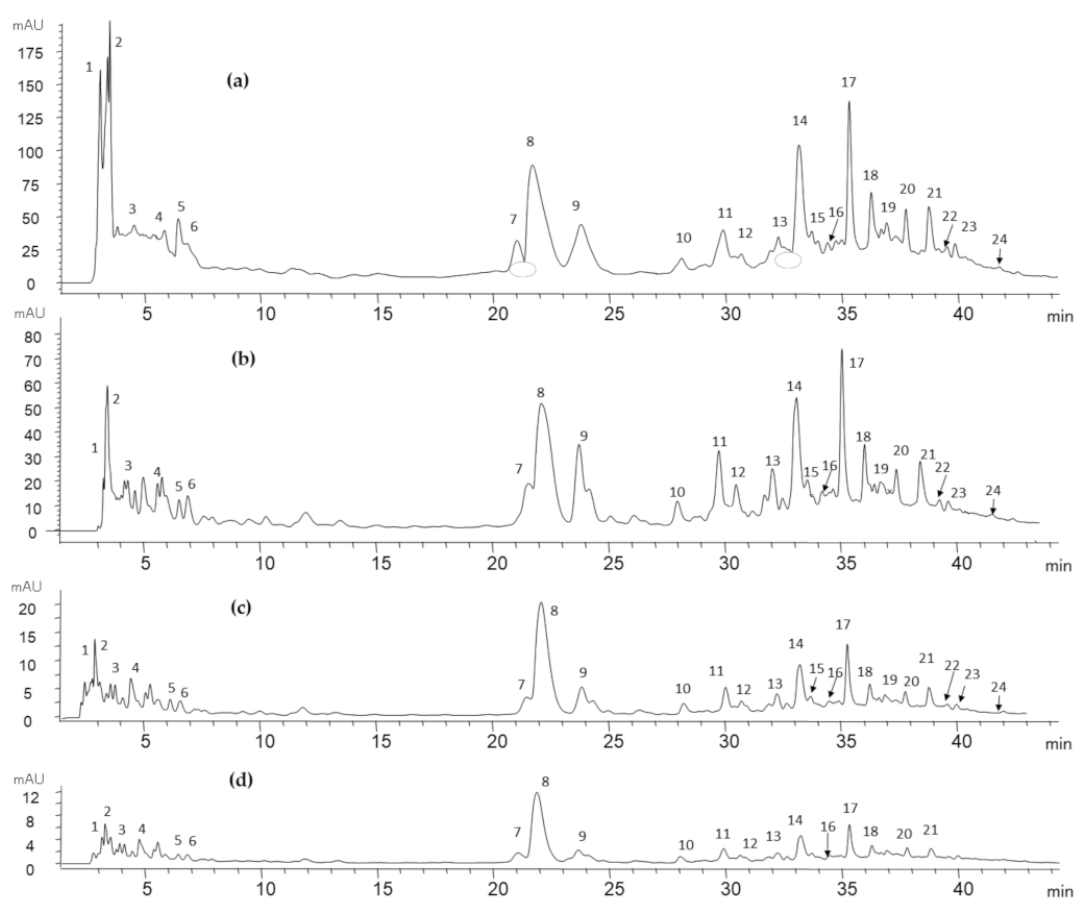

Figure 2. HPLC C18 chromatogram of phenolic compounds from (a) BM-S, (b) Brazil nut (Bertholletia excelsa HBK), (c) cake and (d) BM-D at $280 \mathrm{~nm}$.

Peaks detected in the first five minutes of the run were identified as organic acids. Those were citric acid (peak 1, Rt $=2.9 \mathrm{~min}$ ), ascorbic acid (peak 3, Rt = $3.8 \mathrm{~min}$ ), and succinic acid (peak $4, \mathrm{Rt}=4.8 \mathrm{~min}$ ), distinguished by their common pattern of fragment ions and agreement with previous reports [12] and other fruits [34,35]. Regarding peak 2 ( $\mathrm{Rt}=3.59 \mathrm{~min}$ ), its precursor ion $\mathrm{m} / \mathrm{z} 87$ was identified as pyruvic acid [36]. The phenolic acids identified were mostly hydroxybenzoic acids (eight compounds in their free or derivatives form of gallic acid, ellagic acid, 4-hydroxybenzoic acid, protocatechuic acid, and vanillic acid) and, to a minor degree, by hydroxycinnamic acids (ferulic acid, and p-coumaric acid) and phenolic aldehyde (vanillin). Peak $5(\mathrm{Rt}=6.4 \mathrm{~min}$ ) corresponded to gallic acid with a precursor ion $m / z 274$ and a daughter ion at $m / z 125$, a match with previous studies of the Brazil nut [12]. Peak 6 ( $\mathrm{Rt}=6.9 \mathrm{~min}$ ), due to the fragment, formed $m / z 169$, the compound was identified as a derivative of gallic acid [12]. Peak 7 ( $\mathrm{Rt}=21.7 \mathrm{~min}$ ) was identified as protocatechuic acid derivative, due to its pattern of fragmentation $\mathrm{m} / \mathrm{z} 153$, 159 , and 124, and in agreement with the values reported in the Brazil nut by John and Shahidi [12], who found a higher abundance of protocatechuic acid and its derivative in the BN skin. Peak $10(\mathrm{Rt}=28.4 \mathrm{~min})$ had an important signal and was identified as 4-hydroxybenzoic acid, confirmed by the UV spectrum of its standard and similarity of molecular ion [M-H] $]^{-} m / z 137$ observed in almond, as previously reported [38]. In peak 11, the UV detected spectrum ( $\mathrm{Rt}=30.2 \mathrm{~min}$ ) corresponded to vanillic acid, with molecular ion $m / z 167$, which at the same time is a product ion peak of $24(\mathrm{Rt}=42.1 \mathrm{~min})$, identified as vanillic acid derivative, coinciding in a previous report $[12,38]$. Peak $13(\mathrm{Rt}=32.4 \mathrm{~min})$ was tentatively identified as vanillin with a precursor ion $\mathrm{m} / \mathrm{z} 151$; although not commonly reported in nuts, the precursor ion was also found in wheat [40]. Peak $17(\mathrm{Rt}=36.28 \mathrm{~min})$ corresponded to the molecular ion [M-H]- $m / z$ 164, indicative of p-coumaric acid, with product ion $m / z 119$, with fragment denominates, such as decarboxylated coumaric acid in walnut, according to Pycia et al. [39]. Peak $18(\mathrm{Rt}=36.4 \mathrm{~min})$, a compound with a high signal, has a similr UV spectrum to ferulic acid $(\lambda \max 230 \mathrm{~nm})$ and matched to the fragment ion $m / z 133$ reported in walnuts [39]. Peak $20(\mathrm{Rt}=37.9 \mathrm{~min})$ showed a fragmentation 
pattern which corresponded to an ellagic acid derivative, conformed to ion $m / z 301$ (corresponding to ellagic acid) found at peak $22(\mathrm{Rt}=39.7 \mathrm{~min})$, with values consistent to the previous report on the Brazil nut [12].

Table 3. HPLC retention times, UV/Vis spectra and MS spectral data of individual phenolics in the Brazil nut (Bertholletia excelsa HBK), BM-S, BM-D, and cake.

\begin{tabular}{|c|c|c|c|c|c|c|}
\hline Peak $^{1}$ & Rt (min) & Assigned Identity & $\mathrm{UV} \lambda_{\max }(\mathrm{nm})$ & {$[\mathrm{M}-\mathrm{H}]^{-} m / z$} & MS/MS $m / z$ & References \\
\hline 1 & 2.9 & Citric acid ${ }^{2}$ & 209 & 191 & 111,173 & {$[12,34]$} \\
\hline 2 & 3.1 & Pyruvic acid $^{2}$ & $227.8(259.7)$ & 87.06 & 59.01 & {$[36]$} \\
\hline 3 & 3.8 & Ascorbic acid ${ }^{2}$ & 289 & 175.03 & $147.2,87.00,69.03$ & [34] \\
\hline 4 & 4.8 & Succinic acid $^{2}$ & 228 & 117.02 & 72.91 & [35] \\
\hline 5 & 6.4 & Gallic acid & 274 & 169.01 & $\begin{array}{c}125.02,107.01,97.03 \\
79.02,69.03,51.02 \\
41.04\end{array}$ & [37] \\
\hline 6 & 6.9 & Gallic acid derivative & 272 & 187 & $125.02,169.01$ & [12] \\
\hline 7 & 21.7 & $\begin{array}{c}\text { Protocatechuic acid } \\
\text { derivative }\end{array}$ & 280 & - & $153.04,109.03,124.03$ & [12] \\
\hline 8 & 22.3 & Catechin & 230,280 & 289.1 & $136.8,150.7,160.8$ & {$[12,38]$} \\
\hline 9 & 24.0 & Catechin derivative & 282 & - & 289.1 & [12] \\
\hline 10 & 28.4 & 4-hydroxybenzoic acid & 252 & 137.03 & $106.64,93.03$ & [38] \\
\hline 11 & 30.2 & Vanillic acid & 259,292 & 167.03 & $152.01,108.02$ & {$[12,39]$} \\
\hline 12 & 30.9 & Epicatechin & 279 & 289.1 & $\begin{array}{c}109.01,121.01,123.03 \\
125.01,137.00\end{array}$ & [38] \\
\hline 13 & 32.4 & Vanillin & 274,309 & 151.05 & $\begin{array}{c}137.05,123.05,109.0 \\
81.0\end{array}$ & [40] \\
\hline 14 & 33.4 & Catechin gallate & $231.8,280.1,(324.8)$ & 441.03 & $\begin{array}{c}109.01,125.00,168.98, \\
289.03\end{array}$ & {$[41,42]$} \\
\hline 15 & 33.8 & Epicatechin gallate & $232.6,280(324.8)$ & 441.19 & $\begin{array}{c}109.08,125.08,137.08 \\
151.10,203.14,245.16 \\
289.16\end{array}$ & [38] \\
\hline 16 & 34.6 & $\begin{array}{l}\text { Epigallocatechin 3-O } \\
\text { gallate }\end{array}$ & $232 ; 280(312)$ & 457.3 & $305.6,169.1,125.02$ & [43] \\
\hline 17 & 35.4 & p-Coumaric acid & 227,310 & 164.05 & $119.05,91.05$ & [39] \\
\hline 18 & 36.4 & Ferulic acid & $(292), 323$ & 193.1 & $177.1,161,133.1$ & [39] \\
\hline 19 & 37.0 & $\begin{array}{c}\text { Taxifolin } \\
\text { (dihydroquercetin) }\end{array}$ & $231.9,(282.8) 309.2$ & 303.05 & $285.05,179.00,125.03$ & [12] \\
\hline 20 & 37.9 & Ellagic acid derivative & 252,360 & 447 & $301,257,229$ & [12] \\
\hline 21 & 38.9 & Quercetin & 232,323 & 301 & 179,151 & {$[12,44]$} \\
\hline 22 & 39.7 & Ellagic acid & 254,368 & 301 & $\begin{array}{c}285,283,257,229, \\
184.92,134.92\end{array}$ & [12] \\
\hline 23 & 40.0 & $\begin{array}{l}\text { Myricetin-3-O- } \\
\text { rhamnoside }\end{array}$ & 253,370 & 463 & 317 & {$[12,45]$} \\
\hline 24 & 42.1 & Vanillic acid derivative & 259,294 & 329 & 167 & [12] \\
\hline
\end{tabular}

${ }^{1}$ Peak numbers correspond to those of Figure $2 ;^{2}$ Organic acids.

In the flavonoid group of the Brazil nut and derivatives samples, six types of flavan3-ols were detected (mainly catechin, epicatechin, and their gallate ester or derivatives), followed by two flavonols (myricetin-3-O-rhamnoside and quercetin), and one flavanonols (taxifolin). Peak $8(R t=22.3 \mathrm{~min})$, peak $9(\mathrm{Rt}=24 \mathrm{~min})$ and peak $14(\mathrm{Rt}=33.4 \mathrm{~min})$ were identified as catechin, catechin derivative, and catechin-gallate, respectively. The catechin had the highest signal in flavonoids and its identification was confirmed by the UV spectrum of its standard and pattern ion $m / z 289$, a common value reported in the Brazil nut and walnut $[12,38]$.

Peak $12(\mathrm{Rt}=30.9 \mathrm{~min})$ and peak $15(\mathrm{R} t=33.8 \mathrm{~min})$ showed a precursor ion $\mathrm{m} / z 289$ and 441, that corresponds to epicatechin and epicatechin gallate, respectively, which was also observed in almond [38]. Peak $16(\mathrm{Rt}=34.6 \mathrm{~min})$ with molecular ion $[\mathrm{M}-\mathrm{H}]^{-} \mathrm{m} / z 457$ was tentatively identified as epigallocatechin 3-O gallate, which exhibited the loss of a typical fragment ion $\mathrm{m} / z 169$ that corresponds to gallic acid. Peak 19 (Rt $=37 \mathrm{~min}$ ) was 
identified as taxifolin (dihydroquercetin), due to the common pattern ion $m / z 303$ and fragmentation pattern $m / z 285$ and 125, values that were also observed in a previous report on the Brazil nut [12]. Quercetin was clearly recognized in peak $21(\mathrm{Rt}=38.9 \mathrm{~min})$ by its principal ion $m / z 301$ and fragmentation pattern $m / z 179$ and 151, consistent with reports of walnut [44]. Myricetin-3-O-rhamnoside was identified in peak 23 ( $\mathrm{Rt}=40 \mathrm{~min}$ ) with [M-H $]^{-} m / z 463$, also observed in reports on the Brazil nut and hazelnut [12,45]. In general, the phenolic characterization of $\mathrm{BN}$ is scarce in the literature. We found individual phenols that were not detected or analyzed in previous reports, such as vanillin, catechin gallate, epicatechin, epicatechin gallate, epigallocatechin 3-O gallate, and myricetin-3-Orhamnoside.

\subsubsection{Individual Phenolic Compounds Content in BN and Derivates}

The quantification of phenolic compounds in the Brazil nut, WBM, BM-S, and BM-D, are shown in Table 4. The BN had a total phenolic content of $575 \mu \mathrm{g} / \mathrm{g}$ f.w., composed of flavonoids (393.4 $\mu \mathrm{g} / \mathrm{g}$ f.w.), phenolic acids (176.1 $\mu \mathrm{g} / \mathrm{g}$ f.w.), and vanillin (5.6 $\mu \mathrm{g} / \mathrm{g}$ f.w.), which is a phenolic aldehyde. This phenolic composition is common in other nuts, showing a predominance of flavonoids and phenolic acids [46].

Table 4. Individual phenolic content ( $\mu \mathrm{g} / \mathrm{g}$ ) in Brazil nut (Bertholletia excelsa HBK), its beverages (WBM and BM-S) and by-products (BM-D and cake) by HPLC-DAD-MS.

\begin{tabular}{|c|c|c|c|c|c|c|c|c|c|c|c|}
\hline \multirow{3}{*}{$\begin{array}{c}\text { Rt (Min) } \\
6.4\end{array}$} & \multirow{2}{*}{$\begin{array}{c}\text { Phenolic Compound } \\
\text { Phenolic Acids }\end{array}$} & \multicolumn{2}{|c|}{$\mathrm{BN}^{1}$} & \multicolumn{2}{|c|}{$\mathrm{WBM}^{*, 1}$} & \multicolumn{2}{|c|}{ BM-S ${ }^{1}$} & \multicolumn{2}{|c|}{ BM-D ${ }^{2}$} & \multicolumn{2}{|c|}{ Cake $^{2}$} \\
\hline & & & & & & & & & & & \\
\hline & Gallic acid & 6.3 & \pm 0.2 & 0.7 & \pm 0.0 & 0.5 & \pm 0.0 & 17.7 & \pm 0.8 & 6.4 & \pm 0.3 \\
\hline 6.9 & Gallic acid derivative & 6.9 & \pm 0.3 & 0.6 & \pm 0.0 & 0.4 & \pm 0.0 & 17.7 & \pm 0.2 & 6.5 & \pm 0.3 \\
\hline 21.7 & Protocatechuic acid derivative & 42.0 & \pm 1.9 & 3.0 & \pm 0.1 & 2.1 & \pm 0.1 & 83.2 & \pm 4.0 & 31.7 & \pm 1.4 \\
\hline 28.4 & 4-hydroxybenzoic acid & 6.5 & \pm 0.3 & 0.5 & \pm 0.0 & 0.4 & \pm 0.0 & 3.7 & \pm 0.0 & 2.2 & \pm 0.1 \\
\hline 30.2 & Vanillic acid & 18.0 & \pm 0.8 & 1.5 & \pm 0.0 & 1.4 & \pm 0.0 & 4.9 & \pm 0.1 & 3.3 & \pm 0.1 \\
\hline 35.4 & p-Coumaric acid & 8.5 & \pm 0.3 & 0.9 & \pm 0.0 & 0.8 & \pm 0.0 & 4.9 & \pm 0.1 & 2.6 & \pm 0.1 \\
\hline 36.4 & Ferulic acid & 4.6 & \pm 0.2 & 0.5 & \pm 0.0 & 0.5 & \pm 0.0 & 1.7 & \pm 0.1 & 1.0 & \pm 0.0 \\
\hline 42.1 & Vanillic acid derivative & 1.6 & \pm 0.1 & 0.2 & \pm 0.0 & 0.2 & \pm 0.0 & 0.6 & \pm 0.0 & 0.5 & \pm 0.0 \\
\hline 37.9 & Ellagic acid derivative & 45.4 & \pm 0.4 & 4.7 & \pm 0.1 & 3.3 & \pm 0.1 & 138.6 & \pm 3.8 & 49.1 & \pm 1.7 \\
\hline 39.7 & $\begin{array}{c}\text { Ellagic acid } \\
\text { Phenolic aldehyde }\end{array}$ & 36.2 & \pm 1.4 & 3.5 & \pm 0.0 & 2.1 & \pm 0.0 & 134.1 & \pm 3.4 & 46.8 & \pm 2.5 \\
\hline 32.4 & $\begin{array}{l}\text { Vanillin } \\
\text { Flavonoids }\end{array}$ & 5.6 & \pm 0.2 & 0.5 & \pm 0.0 & 0.5 & \pm 0.0 & 1.3 & \pm 0.1 & 1.2 & \pm 0.0 \\
\hline 22.3 & Catechin & 175.4 & \pm 7.9 & 21.6 & \pm 0.5 & 20.2 & \pm 0.5 & 127.6 & \pm 3.0 & 79.7 & \pm 3.3 \\
\hline 24.0 & Catechin derivative & 86.1 & \pm 2.6 & 9.2 & \pm 0.5 & 8.9 & \pm 0.5 & 25.7 & \pm 1.2 & 18.3 & \pm 0.9 \\
\hline 30.9 & Epicatechin & 21.8 & \pm 0.7 & 1.5 & \pm 0.0 & 1.4 & \pm 0.0 & 16.2 & \pm 0.4 & 8.0 & \pm 0.1 \\
\hline 33.4 & Catechin-gallate & 71.0 & \pm 1.7 & 8.5 & \pm 0.1 & 8.2 & \pm 0.1 & 24.8 & \pm 0.6 & 16.7 & \pm 0.3 \\
\hline 33.8 & Epicatechin-gallate & 14.3 & \pm 0.4 & 1.4 & \pm 0.0 & 1.3 & \pm 0.0 & 13.6 & \pm 0.2 & 6.3 & \pm 0.2 \\
\hline 34.6 & Epigallocatechin 3-O-gallate & 7.4 & \pm 0.3 & 0.3 & \pm 0.0 & 0.2 & \pm 0.0 & 11.0 & \pm 0.3 & 4.3 & \pm 0.1 \\
\hline 37.0 & Taxolin (dihydroquercetin) & \multicolumn{2}{|c|}{-} & \multicolumn{2}{|c|}{-} & \multicolumn{2}{|c|}{-} & \multicolumn{2}{|c|}{-} & \multicolumn{2}{|r|}{ 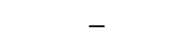 } \\
\hline 38.9 & Quercetin & 6.7 & \pm 0.2 & 0.9 & \pm 0.0 & 0.9 & \pm 0.0 & 0.2 & \pm 0.0 & 1.0 & \pm 0.0 \\
\hline \multirow[t]{5}{*}{40.0} & Myricetin-3-O-rhamnoside & 10.6 & \pm 0.5 & 0.2 & \pm 0.0 & 0.2 & \pm 0.0 & 6.8 & \pm 0.4 & 3.6 & \pm 0.0 \\
\hline & Total phenolic acids & 176.1 & \pm 5.8 & 16.0 & \pm 0.4 & 11.8 & \pm 0.3 & 407.1 & \pm 12.5 & 150.3 & \pm 6.5 \\
\hline & Phenolic aldehyde & 5.6 & \pm 0.2 & 0.5 & \pm 0.0 & 0.5 & \pm 0.0 & 1.3 & \pm 0.1 & 1.2 & \pm 0.0 \\
\hline & Total flavonoids & 393.4 & \pm 14.4 & 43.7 & \pm 1.2 & 41.1 & \pm 1.1 & 225.9 & \pm 6.1 & 138.0 & \pm 5.0 \\
\hline & Total phenolic compounds & 575.0 & \pm 20.4 & 60.2 & \pm 1.6 & 53.3 & \pm 1.4 & 634.3 & \pm 18.6 & 289.4 & \pm 11.5 \\
\hline
\end{tabular}

${ }^{*}$ Value of WBM was estimated from their fractions; ${ }^{1}$ Expressed on fresh weight basis.; ${ }^{2}$ Expressed on dry weight basis.; - Detected but not quantified.

According to Table 4, the predominant flavonoids of $\mathrm{BN}$, in free or derivative form, were catechin and epicatechin, and at a lower level of concentration were quercetin, taxifolin, and myricetin-3-O-rhamnoside. These compounds belong mainly to flavan-3-ols and flavonols subgroups. This profile is consistent with the general characteristics of the nuts, where the flavan-3-ols, flavonols, and anthocyanins are considered to be the main flavonoids [47]. Moreover, previous studies also consider catechin and its derivatives as one of the main flavonoids present in BN [30,48]. With respect to the phenolic acids of BN, 
the most abundant phenolics were mainly hydroxybenzoic acids, free and its derivatives, among them ellagic acid, protocatechuic acid, and vanillic acid. The results are consistent with previous reports of $\mathrm{BN}$, indicating the predominance of gallic acid and protocatechuic acid $[12,30,48]$. In addition, the present study agreed with those reported for other nuts comprised mainly of hydroxybenzoic acids. For example, in walnuts, pecans, and pistachios, gallic acid and its derivatives were the most abundant; in hazelnuts, the gallic acid and the protocatechuic acid were most prevalent; and in almonds, protocatechuic, vanillic, and p-hydroxybenzoic acid dominated [46]. Considering the above, the phenolic profile obtained from the BN showed several common aspects with previous studies, but also noted distinctions that contribute to the characterization.

Regarding the beverages obtained from Brazil nuts, according to Table 4, the WBM and BM-S had a similar total phenol content of 60.2 and $53.3 \mu \mathrm{g} / \mathrm{g}$ f.w., respectively. In both beverage samples, flavonoids, such as catechin, epicatechin, and their derivatives, stand out, but an inverse fact was seen in BM-D and cake by-products, where phenolic acids are more abundant than flavonoids (Table 4). These results suggested that most of the flavonoids in $\mathrm{BN}$ are water-soluble due to the effect of beverage processing and are transferred to the aqueous phase, but their presence is reduced in nonwater-soluble matrices such as BM-D and cake. This fact agrees with the report of John and Shahidi [12], who noted that phenolic acids, such as protocatechuic acid, gallic acid, and ellagic acid, are mainly concentrated in the BN skin, which was the non-water-soluble matrix found primarily in the BM-D. In the literature, reports on the phenolic profile of vegetable milks are scarce, with the exception of soy milk, which showed a higher level of phenolic content than that observed for Brazil nut beverages studied here (WBM and BM-S). In soy milk, the level of flavonoids, such as isoflavonoids, are very important and may vary according to the variety of soy legume [49].

The phenolic compounds identified as predominant in $\mathrm{BN}$ and its derivatives, such as flavan-3-ols (catechin and epicatechin) and hydroxybenzoic acids (ellagic acid, vanillic acid, and protocatechuic acid), are widely recognized in the literature with promising effects associated with human health promotion and the prevention of disease risk by acting as an antioxidant, anti-inflammatory, cardioprotective, and antimicrobial, among others [50,51]. Therefore, Brazil nuts (BN), beverages of BN (WBM and BM-S), and its by-products, represent a contribution to the diet through their phenolic phytochemicals.

\subsection{Lipids and Other Lipophilic Components}

\subsubsection{Fatty Acid Profile}

The identified fatty acids by gas chromatography are presented in Table 5 . The fatty acids of the Brazil nut (BN) mostly consisted of unsaturated fatty acids (UFA), more than $70 \%$ of total fatty acids, mainly linoleic acid $(36.9 \%)$ and oleic acid $(36.4 \%)$. The rest of the fatty acids consisted of palmitic acid $(15.9 \%)$, stearic acid $(10.32 \%)$, and in minimal amounts, palmitoleic acid $(0.24 \%)$ and arachidic acid $(0.1 \%)$. This fatty acid profile of the $\mathrm{BN}$ was similar to those reported in the literature [48]. Moreover, it was observed that the fatty acid profile of the Brazil nut (BN), WBM fractions, and cake, did not show a significant difference $(p<0.05)$, demonstrating that the hydrothermal grinding (homogenization) to obtain the beverage from $\mathrm{BN}$ does not affect the percentage composition of the fatty acid between raw material and its beverages (WBM and BM-S) and by-products (BM-D, BM-D and cake). 
Table 5. Fatty acid content of the Brazin nut (Bertholletia excelsa HBK), WBM fractions, and cake.

\begin{tabular}{|c|c|c|c|c|c|}
\hline \multirow{2}{*}{ Fatty Acids (FA) \% } & \multirow{2}{*}{$\mathbf{B N}$} & \multicolumn{3}{|c|}{ WBM Fractions } & \multirow{2}{*}{ Cake } \\
\hline & & BM-S & BM-D & BM-F & \\
\hline Palmitic (C16:0) & $15.95 \pm 1.06^{\mathrm{a}}$ & $15.35 \pm 0.15^{\mathrm{a}}$ & $15.36 \pm 0.05^{\mathrm{a}}$ & $15.30 \pm 0.05^{\mathrm{a}}$ & $15.17 \pm 0.11^{\mathrm{a}}$ \\
\hline Palmitoleic (C16:1) & $0.24 \pm 0.01^{\mathrm{b}}$ & $0.20 \pm 0.02^{b}$ & $0.21 \pm 0.02^{b}$ & $0.22 \pm 0.02^{b}$ & $0.22 \pm 0.01^{b}$ \\
\hline Stearic (C18:0) & $10.32 \pm 2.59^{c}$ & $9.84 \pm 0.24^{\mathrm{c}}$ & $10.09 \pm 0.15^{\mathrm{c}}$ & $9.57 \pm 0.03^{c}$ & $9.52 \pm 0.17^{c}$ \\
\hline Oleic (C18:1) & $36.40 \pm 5.68^{d}$ & $36.66 \pm 1.23^{d}$ & $36.59 \pm 0.34^{d}$ & $35.85 \pm 0.18^{d}$ & $35.33 \pm 0.45^{\mathrm{d}}$ \\
\hline Linoleic (C18:2) & $36.99 \pm 7.22 \mathrm{e}$ & $37.86 \pm 1.30^{\mathrm{e}}$ & $37.64 \pm 0.47^{\mathrm{e}}$ & $38.97 \pm 0.10^{\mathrm{e}}$ & $39.64 \pm 0.52 \mathrm{e}$ \\
\hline Arachidic (C20:0) & $0.10 \pm 0.06^{\mathrm{f}}$ & $0.09 \pm 0.01^{\mathrm{f}}$ & $0.11 \pm 0.03^{f}$ & $0.09 \pm 0.01^{\mathrm{f}}$ & $0.11 \pm 0.02^{f}$ \\
\hline Total Saturated (SFA) & $26.37 \pm 3.71^{g}$ & $25.28 \pm 0.39 \mathrm{~g}$ & $25.56 \pm 0.23^{g}$ & $24.97 \pm 0.09 g$ & $24.81 \pm 0.30^{\mathrm{g}}$ \\
\hline Total Unsaturated (UFA) & $73.63 \pm 12.90^{h}$ & $74.72 \pm 2.55^{h}$ & $74.44 \pm 0.82^{h}$ & $75.03 \pm 0.30^{h}$ & $75.19 \pm 0.98^{h}$ \\
\hline Polyunsaturated (PUFA) & $36.99 \pm 7.22^{\mathrm{i}}$ & $37.86 \pm 1.30^{\mathrm{i}}$ & $37.64 \pm 0.47^{\mathrm{i}}$ & $38.97 \pm 0.10^{\mathrm{i}}$ & $39.64 \pm 0.52^{\mathrm{i}}$ \\
\hline Monounsaturated (MUFA) & $36.64 \pm 5.69^{j}$ & $36.86 \pm 1.25^{j}$ & $36.80 \pm 0.36^{j}$ & $36.07 \pm 0.19^{\mathrm{j}}$ & $35.55 \pm 0.46^{\mathrm{j}}$ \\
\hline
\end{tabular}

Data are expressed as means $\pm \mathrm{SD}(n=3)$. Values with different superscript letters in each row are significantly different $(p<0.05)$.

Regarding the beverages, the importance of fatty acids falls mainly on WBM beverage due to the level of total lipids they contain (5.24/100 $\mathrm{g}$ f.w.), something that minimally influences the BM-S beverage, which contains only $0.25 / 100 \mathrm{~g}$ f.w. in total lipids. The predominant level of unsaturated fatty acids (MUFA and PUFA) compared to saturated is common in vegetable milk alternatives, as is the case of soy, rice, almond, and cashew milk alternatives, which usually contain more than $70 \%$ UFA of the total fatty acids, with the exception of coconut milk, with a predominance of saturated fat [4]. This feature of UFA is considered beneficial for potential health-promoting effects, such as reducing LDL cholesterol, increasing HDL, and controlling cardiovascular events [52]. However, due to the oxidation susceptibility and hydrolytic rancidity of the UFA in the beverage obtained from $\mathrm{BN}$, it is necessary to control the oxidative stabilization processes. Considering the above and the composition of fatty acids (Table 5), the cake and BM-F by-products are food ingredients with "healthy fat" characteristics.

\subsubsection{Free Fatty Acids and Monoglycerides}

Free fatty acids (FFAs) and mono- and diglycerides are associated with shelf life and quality of edible oils and are normally removed by refining processes because they are susceptible to autooxidation. In the case of vegetable milks the rancidification phenomenon is attributed to lipolysis of triglycerides and increase of FFA, causing off flavor and the deterioration of the beverage [53]. As expected, our work observed corresponding FFA content (Table 6) and total lipid content (Table 1), in the samples.

Table 6. Free fatty acids, monoglycerides, phytosterols, $\beta$-Sitosterol, and squalene content of the Brazil nut (Bertholletia excelsa HBK), its beverages (WBM and BM-S), and by-products (BM-D, BM-F, and cake).

\begin{tabular}{|c|c|c|c|c|c|c|c|c|c|c|c|}
\hline \multirow{2}{*}{\multicolumn{2}{|c|}{ Compound }} & \multirow{2}{*}{\multicolumn{2}{|c|}{$\frac{\text { Raw Material }}{\text { BN }^{1}}$}} & \multicolumn{4}{|c|}{ Beverages } & \multicolumn{4}{|c|}{ Byproducts } \\
\hline & & & & \multicolumn{2}{|c|}{ WBM $^{1}$} & \multicolumn{2}{|c|}{$\mathrm{BM} \mathrm{S}^{1}$} & \multicolumn{2}{|c|}{ BM-D ${ }^{2}$} & BM-F ${ }^{2}$ & Cake $^{2}$ \\
\hline & $(\mathrm{mg} / 100 \mathrm{~g})$ & 346 & $\pm 61^{\mathrm{a}}$ & 51.3 & $\pm 12^{\mathrm{ab}}$ & 3.11 & $\pm 0.7^{\mathrm{b}}$ & 181.4 & $\pm 41^{\mathrm{ab}}$ & $794 \pm 172^{c}$ & $80.5 \pm 4.1^{\mathrm{ab}}$ \\
\hline FFA & (g/100 g oil) & 0.59 & $\pm 0.10^{\mathrm{abc}}$ & 1.0 & $\pm 0.2^{a b c}$ & 1.24 & $\pm 0.3^{\mathrm{bc}}$ & 1.24 & $\pm 0.28^{b}$ & $0.98 \pm 0.2^{\mathrm{abc}}$ & $0.18 \pm 0.01^{\mathrm{a}}$ \\
\hline \multirow{2}{*}{ Monoglycerides } & $(\mathrm{mg} / 100 \mathrm{~g})$ & 110.8 & $\pm 32^{\mathrm{a}}$ & 113.5 & $\pm 34^{\mathrm{a}}$ & 5.66 & $\pm 0.8^{\mathrm{a}}$ & 304.3 & $\pm 65^{\mathrm{a}}$ & $1789 \pm 58^{b}$ & $66.3 \pm 33^{a}$ \\
\hline & (g/100 g oil) & 0.19 & $\pm 0.05^{\mathrm{a}}$ & 2.20 & $\pm 0.6^{\mathrm{b}}$ & 2.25 & $\pm 0.3^{\mathrm{b}}$ & 2.08 & $\pm 0.45^{\mathrm{b}}$ & $2.20 \pm 0.6^{b}$ & $0.15 \pm 0.07^{a}$ \\
\hline Total & (mg/100 g) & 18.9 & $\pm 6^{\mathrm{a}}$ & 3.1 & $\pm 0.3^{c}$ & 0.22 & $\pm 0.04 \mathrm{bc}$ & 7.2 & $\pm 1.3^{\mathrm{abc}}$ & $47.8 \pm 5^{\mathrm{d}}$ & $25.5 \pm 0.8^{\mathrm{ae}}$ \\
\hline tocopherol & (mg/100 g oil) & 32.3 & $\pm 11^{\mathrm{a}}$ & 59.9 & $\pm 6.1^{\mathrm{b}}$ & 88.1 & $\pm 17^{\mathrm{b}}$ & 49.3 & $\pm 9^{\mathrm{ab}}$ & $58.77 \pm 6^{a b}$ & $57.6 \pm 1.8^{a b}$ \\
\hline \multirow{2}{*}{$\gamma$-Tocopherol } & $(\mathrm{mg} / 100 \mathrm{~g})$ & 16.5 & $\pm 4.6^{\mathrm{a}}$ & 2.4 & $\pm 0.08^{b}$ & 0.18 & $\pm 0.04^{\mathrm{b}}$ & 5.76 & $\pm 1.1^{\mathrm{b}}$ & $37.4 \pm 1^{\mathrm{c}}$ & $19.9 \pm 1.9^{\mathrm{a}}$ \\
\hline & (mg/100 g oil) & 28.3 & $\pm 7^{\mathrm{ac}}$ & 47.1 & $\pm 1.4^{\mathrm{abc}}$ & 73.5 & $\pm 14^{\mathrm{b}}$ & 39.5 & $\pm 7^{\mathrm{c}}$ & $45.98 \pm 1^{\mathrm{abc}}$ & $45.1 \pm 4.3^{\mathrm{abc}}$ \\
\hline \multirow{2}{*}{$\alpha$-Tocopherol } & $(\mathrm{mg} / 100 \mathrm{~g})$ & 2.4 & $\pm 2^{\mathrm{a}}$ & 0.7 & $\pm 0.26^{\mathrm{a}}$ & 0.04 & $\pm 0.01^{\mathrm{a}}$ & 1.4 & $\pm 0.2^{\mathrm{a}}$ & $10.4 \pm 4^{b}$ & $5.5 \pm 1.1^{\mathrm{ab}}$ \\
\hline & (mg/100 g oil) & 4.02 & $\pm 1.3^{\mathrm{a}}$ & 12.8 & $\pm 4.8^{\mathrm{a}}$ & 14.61 & $\pm 2.9^{\mathrm{a}}$ & 9.78 & $\pm 1.5^{\mathrm{a}}$ & $12.79 \pm 2.5^{\mathrm{a}}$ & $12.5 \pm 2.5^{\mathrm{a}}$ \\
\hline \multirow{2}{*}{$\beta$-Sitosterol } & $(\mathrm{mg} / 100 \mathrm{~g})$ & 60.2 & $\pm 15^{\mathrm{a}}$ & 7.1 & $\pm 0.9^{b}$ & 0.73 & $\pm 0.23^{b}$ & 30.7 & $\pm 6^{\mathrm{ab}}$ & $105 \pm 11^{c}$ & $62.1 \pm 3^{a}$ \\
\hline & (mg/100 g oil) & 102.8 & $\pm 26^{\mathrm{b}}$ & 138.4 & $\pm 17^{\mathrm{ab}}$ & 289.5 & $\pm 89^{\mathrm{a}}$ & 210.1 & $\pm 43^{\mathrm{ab}}$ & $129 \pm 13^{a b}$ & $140.4 \pm 6^{\mathrm{ab}}$ \\
\hline \multirow{2}{*}{ Squalene } & $(\mathrm{mg} / 100 \mathrm{~g})$ & 217.5 & $\pm 13^{\mathrm{a}}$ & 13.2 & $\pm 2.8^{\mathrm{b}}$ & 0.69 & $\pm 0.11^{\mathrm{b}}$ & 40.1 & $\pm 11^{\mathrm{b}}$ & $207.6 \pm 41^{a}$ & $123.6 \pm 8^{c}$ \\
\hline & (mg/100 g oil) & 371.7 & $\pm 23^{a}$ & 256.7 & $\pm 50^{\mathrm{a}}$ & 272.62 & $\pm 43^{\mathrm{a}}$ & 274.8 & $\pm 74^{\mathrm{a}}$ & $255.4 \pm 50^{a}$ & $279.7 \pm 18^{a}$ \\
\hline
\end{tabular}

${ }^{1} \mathrm{mg} / 100 \mathrm{~g}$ is expressed on fresh weight basis; ${ }^{2} \mathrm{mg} / 100 \mathrm{~g}$ is expressed on dry weight basis. Data are expressed as means $\pm \mathrm{SD}(n=2)$. The different superscript letters within a row are significantly different $(p<0.05)$. 
The FFA concentration of BN (raw material), expressed in oil basis, was around $0.6 / 100 \mathrm{~g}$ oil, consistent with one previously reported, in a range of $0.2-0.8 / 100 \mathrm{~g}$ oil [54], a value within the quality standards established by the European community $(\leq 2 / 100 \mathrm{~g}$ oil, expressed in oleic acid) to be considered as virgin oil [55]. When the FFA of BN and its beverages (WBM and BM-S, with 1 and 1.24/100 g oil, respectively) were compared, there was no significant difference $(p \leq 0.05)$. However, the slight increase observed can be attributed to triglyceride lipolysis that might occur during the homogenization process, when subjected to high temperatures $\left(75^{\circ} \mathrm{C}\right)$ in an aqueous medium.

Although FFA concentration is considered a promising quality indicator for vegetable milks, reports are scarce. The FFA obtained for the WBM and BM-S beverage had a concentration of 54.9 and $3.11 \mathrm{mg} / 100 \mathrm{~g}$ f.w., respectively, a lower value than almond milk (around $380 \mathrm{mg} / 100 \mathrm{~mL}$ )[29] and soybean milk (99 mg/100 mL)[56], as previously reported. As for the by-products (BM-D, BM-F fraction, and cake), there was also no significant difference with the raw material in terms of FFA concentration (on oil basis), which ranged from $0.18-1.24 \mathrm{mg} / \mathrm{g}$ oil, showing that they were not affected by the hydrothermal process of beverage production.

In relation to monoglycerides, expressed in oil bases, the BN had 0.19/100 $\mathrm{g}$ oil, comparable to most oilseeds in the range of $0.2-0.4 / 100 \mathrm{~g}$ oil. However, a significant increase $(p<0.05)$ in monoglycerides was observed between the $\mathrm{BN}$ (raw material) and beverages (WBM and BM-S, both with 2.2/100 g oil), which suggests the occurrence of lipid hydrolysis during beverage processing. This can be attributed to a reaction with the water molecules, oxygen, exposure to high temperature $\left(75^{\circ} \mathrm{C}\right)$, and, to a lesser extent, by enzymatic hydrolysis (a considerable part would be inactivated by heat treatment).

As for the by-products, a significant difference $(p<0.05)$ was found in the concentration of monoglycerides. Despite the cake coming from the hot water grinding stage (homogenization), its monoglyceride content was low (0.15/100 g oil) with around 2/100 g oil. This can be explained by the protective and barrier effect of the matrix structure of the cake, which contains within it the lipid molecules that were not released in the crushing, thus avoiding contact and reaction with agents that promote lipolysis.

\subsubsection{Phytosterols, Tocopherols, and Squalene}

These compounds are found in minor quantities, mainly in edible oils of plant origin, appreciated for their antioxidant capacity and biological properties. Therefore, it was considered of interest to evaluate the composition of these minor compounds in the Brazil nut, its derived beverage (WBM and BM-S), and by-products (BM-D, BM-F and cake). According to the results obtained in Table 6, the BN had a total tocopherol content of $18.9 \mathrm{mg} / 100 \mathrm{~g}$ f.w., mainly comprised of $\gamma$-tocopherol (16.5 mg/100 g f.w.) and, to a lower extent, by $\alpha$-tocopherol $(2.3 \mathrm{mg} / 100 \mathrm{~g} \mathrm{~d} . w$.$) . It is interesting to remark that the \gamma$-tocopherol content obtained from BN (28.3 mg/100 g oil) may be higher than other edible oils, such as sunflower oil (1.4-4.5 mg/100 g oil) and olive oil (0.9-1.3 mg/100 g oil), which would be an interesting feature considering that $\gamma$-Tocopherol is recognized as a potent inhibitor of free radicals against lipid oxidation [57]. Regarding the content of $\beta$-sitosterol, the BN had $102.8 \mathrm{mg} / 100 \mathrm{~g}$ oil, which was consistent with a previous report but shows a relatively low level if compared to other nuts (range of $97-468 \mathrm{mg} / 100 \mathrm{~g}$ oil) [58]. On the other hand, the most abundant lipid bioactive minor component found in BN lipid was squalene with $371.68 \mathrm{mg} / 100 \mathrm{~g}$ oil, a great value compared to most other plant sources [59].

The hydrothermal process for the production of the beverage from $\mathrm{BN}$, according to the results of Table 6, in an oil base, had a positive effect on the increase of total tocopherol and $\beta$-sitosterol in the beverages (WBM and BM-S) with respect to the raw material. This increase could be linked to the extractability power of the hydrothermal process, hydrolysis of conjugated (esterified) forms, their affinity to emulsion formation, and their hydrophobic character as glycosylated sterols. In the literature, despite being scarce, the WBM beverage (with $3.1 \mathrm{mg} / 100 \mathrm{~g} \mathrm{f.w.)}$ is suggested have a total tocopherol comparable to the range reported in vegetable milks, roughly $0.5-3.9 \mathrm{mg} / 100 \mathrm{~mL}$ [5]. Although there are no reports 
of squalene content in vegetable milks, its high content in $\mathrm{BN}$ compared to other vegetable sources (explained in the previous paragraph) could consequently estimate that the WBM beverage (with $14.4 \mathrm{mg} / 100 \mathrm{~g}$ f.w.) contains a higher squalene concentration than other vegetable milks.

In relation to by-products, according to Table 6 and expressed on a dry basis, BM-F has the highest content of lipophilic bioactive minor components, followed by cake and BM-D, which are consistent with the lipid content of each sample (Table 1). In oil bases, no significant differences of these minor components were observed among the by-products, nor within the raw material $(\mathrm{BN})$, which reiterates their stability after beverage processing. In a previous report, using cake (beverage by-product) from the Peruvian Brazil nut, a similar composition was also found: total tocopherol (56.6 mg/100 $\mathrm{g}$ oil) and $\beta$-sitosterol (183.9 mg/100 g oil) and squalene (531.7 mg/100 g oil) [60]. In general, it is possible to say that the lipophilic bioactive components of the beverage by-products are stable against the hydrothermal process (homogenization stage) and BM-F and cake contain a substantial level.

\subsection{Characterization of Proteins in Brazil Nut and Derivatives}

The Brazil nut and its derivatives had a significant content of proteins, except for the BM-F. In dry weight $(w / w)$, BN had $16 \%$, BM-S $40.5 \%$, BM-D $57 \%$, and cake $17 \%$ of protein. This remarkable protein level encouraged us to characterize this fraction, which was performed by SDS-PAGE electrophoresis and mass spectrometry of the protein bands using MALDI TOF/TOF analysis. Figure 3 show the electrophoretic profile of the different proteins characterized by the $\mathrm{BN}$ and its derivatives.

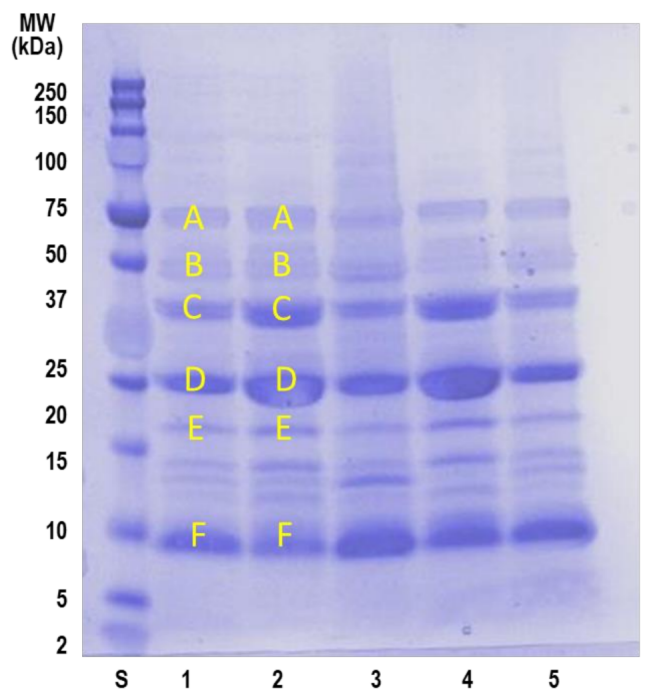

Figure 3. SDS-PAGE profile of Brazil nut products. Lane 1: Brazil nut (Bertholletia excelsa HBK); Lane 2: BN protein isolate; Lane 3: BM-D; Lane 4: BM-S; Lane 5: Cake. A to F bands in lanes 1 and 2 were in-gel digested for identification by MALDI TOF/TOF.

The main bands appeared in all samples analyzed and corresponded to molecular weights between 75-10 kDa. Mass spectrometry identification after in-gel digestion of the proteins enabled the assignment of three different bands to $11 \mathrm{~S}$ globulin $(\mathrm{B}, \mathrm{C}$, and $\mathrm{D}$ band), which points to the occurrence of different electrophoretic forms of this protein (see Table 7). In addition, $\mathrm{E}$ and $\mathrm{F}$ bands could be putatively assigned to the two reported chains of $2 \mathrm{~S}$ sulfur-rich storage protein and $2 \mathrm{~S}$ albumin, although identification must be contrasted by other methods. Similarly, band A, with the highest molecular weight but with the lowest occurrence, matched with convicilin from Pisum sativum (Garden pea). The proteins identified and the observed occurrence is comparable to previous reports where $11 \mathrm{~S}$ protein was found to be the most abundant protein with around $60-70 \%$ of the total 
protein content of the BN, followed by $2 \mathrm{~S}(19-30 \%)$ and 7S (8-10\%) [61]. Furthermore, in Figure 3, all products kept a characteristic profile, but BM-S (Lane 4) showed a higher band intensity above $20 \mathrm{kDa}$, suggesting a higher concentration of convicilin and 11S globulin protein than BM-D (Lane 3) and cake (Lane 5). These proteins have been found to be soluble at a neutral and alkaline $\mathrm{pH}$, which explains this behavior [62]. Among Brazil nut proteins, a $9 \mathrm{kDa}$ methionine-rich $2 \mathrm{~S}$ albumin has been identified as the major allergen in this nut [63]. This protein could correspond with the electrophoretic band F present in all products. Several experiments are in progress to evaluate the resistance of these proteins to gastrointestinal digestion and to identify potential allergenic protein fragments.

Table 7. Identification of peptide fragments of Brazil nut (Bertholletia excelsa HBK) by in-gel digestion of electrophoretic bands.

\begin{tabular}{cccccc}
\hline Band & Tryptic Peptide (Ion) & Protein Fragment & Sequence & Protein Name & Entry Number \\
\hline B & 1145.44 & $194-202$ & RSQKQRGER & 11S globulin & Q84ND2 (Bertholletia excelsa) \\
B & 1202.43 & $338-327$ & MMAPLWRLNA & 11S globulin & Q84ND2 (Bertholletia excelsa) \\
B & 1145.49 & $434-442$ & RLSQEEARR & 11S globulin & Q84ND2 (Bertholletia excelsa) \\
B & 2256.85 & $42-60$ & QYRLEAEAGVSE & 11S globulin & Q84ND2 (Bertholletia excelsa) \\
C & 1202.46 & $184-193$ & VWDYTDQ & 1S globulin & Q84ND2 (Bertholletia excelsa) \\
C & 999.37 & $90-97$ & LYYVTQGR & 11S globulin & Q84ND2 (Bertholletia excelsa) \\
C & 882.39 & $131-137$ & QDQHQKV & 11S globulin & Q84ND2 (Bertholletia excelsa) \\
C & 1202.55 & $185-194$ & HFFLAGNIQR & 11S globulin & Q84ND2 (Bertholletia excelsa) \\
D & 1165.4 & $367-376$ & GETVFDDNLR & 11S globulin & Q84ND2 (Bertholletia excelsa) \\
D & 1229.54 & $422-433$ & RGIPVGVLANAY & 11S globulin & Q84ND2 (Bertholletia excelsa) \\
D & 2315.75 & $49-70$ & GVSEVWDYTD & 11S globulin & Q84ND2 (Bertholletia excelsa) \\
\hline
\end{tabular}

\subsection{Selenium and Other Minerals}

\subsubsection{Selenium Content}

The Brazil nut is recognized as a food with extraordinary concentrations of Selenium (Se), an essential micromineral that performs various physiological functions and is attributed with favorable health effects [3]. In the present study, the Se content of the Brazil nut (BN), its beverages (B-S), and by-products (BM-D, BM-F, and cake) was determined by ICP-MS (Table 8). Brazil nuts had a Se content of $36.28 \mu \mathrm{g} / \mathrm{g}$ f.w. This value was within the range of $10-78 \mu \mathrm{g} / \mathrm{g}$ f.w. of the Se content previously reported [64].

Concerning the BN beverages, the WBM showed a higher Se content (15 $\mu \mathrm{g} / 100 \mathrm{~g}$ f.w.) than BM-S $(8.3 \mu \mathrm{g} / 100 \mathrm{~g}$ f.w.) This difference can be attributed mainly to the fact that the WBM has a higher protein content, roughly double that of BM-S, a nutrient associated with selenoamino acids. Another factor that contributed to the Se level of WBM was the participation of BM-D, with $537 \mu \mathrm{g}$ Se/100 g d.w. According to the Food and Nutrient Database of USDA [65], commercial vegetable milks (soybean, almond, rice, and coconut milk) register Se levels up to a maximum of $2.3 \mu \mathrm{g} / 100 \mathrm{~g}$ f.w., values much lower than those registered in the WBM and BM-S beverage. However, some previous reports on BN beverages showed higher Se levels than our study. Sartori et al. [9] obtained $106 \mu g$ Se $/ 100 \mathrm{~mL}$, using a BN with Se content of $871.4 \mu \mathrm{g} / 100 \mathrm{~g} \mathrm{f.w}$. and defatting the BN before the beverage is produced. The authors used a higher raw material to water ratio $(1: 2, w / v)$ than in our work $(1: 7, w / v)$. In another study, when $\mathrm{BN}$ beverage powder (obtained by spray-drying) was dissolved in water $(10 \mathrm{~g}$ in $100 \mathrm{~mL})$, the Se concentration was $120 \mu \mathrm{g} / 100$ $\mathrm{mL}$. This study had also used defatted BN and raw material to water ratio of 1:2 (w/v) [8]. Considering the above, the raw materials and technological processes employed are factors that influenced the Se level of our beverages compared to others previously reported.

The presence of Selenium linked to proteins in Brazil nuts is well known in the literature. Still, it is interesting to note the difference in Se level between BN $(3721 \mu \mathrm{g} / 100 \mathrm{~g}$ d.w.) and cake (229 $\mu \mathrm{g} / 100 \mathrm{~g}$ d.w.) observed in the present study after beverage processing, even though both have a similar protein content (about 16\%,w/w, dry weight). This 
variation could be explained by the solubility properties of proteins and its selenoamino acids. According to protein identification (Table 7), albumin proteins (2S albumin, 2S SP1 and 2SP2) are known to be more soluble in aqueous media than $11 S$ globulin and convicilin (soluble in saline solution). In addition, the albumin protein of $\mathrm{BN}$ (about $30 \%$ of the total protein) is considered to be the most abundant of the selenoamino acids (mainly methionine and cysteine amino acids) [66].

Our work suggests that one BN ( $\sim \mathrm{g}$ f.w.) could provide about $260 \%$ of the dietary reference value (DRV) (70 $\mu \mathrm{g}$ Se/day); and a cup ( $240 \mathrm{~mL})$ of BM and BM-S beverages can contribute around 50 and $30 \%$ of DRV, respectively. In by-products, the Se level of cake and BM-D in $10 \mathrm{~g}$ d.w. are able to provide 32.7 and 76.7\% of DVR. To this important contribution of Se from BN and its beverages must be added its recognized good bioavailability, due to its occurrence in organic form. According to Lima [64], by X-ray absorption near edge structure (XANES) spectra study, the Se contained in BN an average of $91 \%$ was present in its organic form, detected as C-Se-C compounds. This characteristic of Se and its recognized biological value in health allow BN and the derivatives studied (beverages and by-product with remarkable Se level) to be considered as an important source of this mineral and its possible application in food as a healthy ingredient.

\subsubsection{Other Minerals Content}

Table 8 show the other minerals quantified in the Brazil nut and its derivatives, omitting from Selenium. In the BN, the content of macrominerals showed the following order of predominance: P (686.05 mg/100 g f.w.), K (576.21 mg/100 g f.w.), Mg (468.85 mg/100 g f.w.), and Ca (186.83 mg/100 g f.w.). In microminerals, those that stood out are: Zn (4.72 mg/100 g f.w.), Fe (3.12 mg/100 g f.w.), and Cu (1.83 mg/100 g f.w.). The values obtained in the present study are similar to those reported by the USDA National Nutrient Database [65] regarding Brazil nuts. Likewise, taking into account the report of dietary reference values (DRV) for nutrients by EFSA [67], for adults over 18 years old, one edible portion of $\mathrm{BN}$ ( $\sim 6$ units and $30 \mathrm{~g}$ ) could provide about $40 \%$ of the daily requirement in $\mathrm{Mg}, \mathrm{P}$, and $\mathrm{Cu}$, followed by $\mathrm{Zn}(12.3 \%), \mathrm{Fe}(8.5 \%), \mathrm{Mn}(7.5 \%)$, and about $5 \%$ in $\mathrm{Ca}$ and $\mathrm{K}$.

Table 8. Mineral content of Brazil nut (Bertholletia excelsa HBK), its beverages (WBM and BM-S), and by-products (BM-D, BM-F, and cake).

\begin{tabular}{|c|c|c|c|c|c|c|c|c|c|c|c|c|c|}
\hline \multirow{3}{*}{$\begin{array}{c}\begin{array}{c}\text { Minerals } \\
\text { (mg/100 g) }\end{array} \\
\mathrm{Mg}\end{array}$} & \multirow{2}{*}{\multicolumn{2}{|c|}{$\frac{\text { Raw Material }}{\text { BN }^{1}}$}} & \multicolumn{4}{|c|}{ Beverages } & \multicolumn{6}{|c|}{ By-Products } & \multirow{3}{*}{$\begin{array}{c}\begin{array}{c}\mathrm{DRV}^{3} \\
\text { (mg/Day) }\end{array} \\
325\end{array}$} \\
\hline & & & \multicolumn{2}{|c|}{ WBM $^{1}$} & \multicolumn{2}{|c|}{ BM-S $^{1}$} & \multicolumn{2}{|c|}{ BM-D ${ }^{2}$} & \multicolumn{2}{|c|}{ BM-F $^{2}$} & \multicolumn{2}{|c|}{ Cake $^{2}$} & \\
\hline & 468.85 & $\pm 25^{\mathrm{a}}$ & 35.89 & $\pm 1.1^{\mathrm{b}}$ & 11.06 & $\pm 0.67^{b}$ & 2301.5 & $\pm 62^{c}$ & 19.27 & $\pm 1.06^{\mathrm{b}}$ & 513.03 & $\pm 8.8^{a}$ & \\
\hline K & 576.21 & $\pm 40^{\mathrm{a}}$ & 77.70 & $\pm 0.7^{\mathrm{b}}$ & 55.13 & $\pm 1.25^{\mathrm{b}}$ & 1949.6 & $\pm 108^{\mathrm{d}}$ & 38.92 & $\pm 1.89^{b}$ & 421.15 & $\pm 44^{\mathrm{c}}$ & 3500 \\
\hline $\mathrm{Ca}$ & 186.83 & $\pm 2.6^{\mathrm{a}}$ & 13.96 & $\pm 2.3^{\mathrm{a}}$ & 2.36 & $\pm 0.27^{\mathrm{a}}$ & 1196 & $\pm 227^{b}$ & 7.79 & $\pm 1.18^{a}$ & 221.62 & $\pm 1.6^{\mathrm{a}}$ & 1000 \\
\hline $\mathrm{P}$ & 686.05 & $\pm 13^{a}$ & 60.59 & $\pm 2.3^{b}$ & 11.38 & $\pm 1.16^{\mathrm{b}}$ & 4605 & $\pm 151^{\mathrm{c}}$ & 23.17 & $\pm 4.38^{\mathrm{b}}$ & 725.11 & $\underset{\mathrm{a}}{ \pm 11.6}$ & 550 \\
\hline $\mathrm{Zn}$ & 4.72 & $\pm 0.1^{\mathrm{a}}$ & 0.43 & $\pm 0.01^{\mathrm{b}}$ & 0.02 & $\pm 0.00^{\mathrm{d}}$ & 36.4 & $\pm 0.27^{\mathrm{e}}$ & 0.59 & $\pm 0.08^{\mathrm{b}}$ & 5.71 & $\pm 0.1^{\mathrm{c}}$ & 11.5 \\
\hline $\mathrm{Cu}$ & 1.83 & $\pm 0.1^{\mathrm{a}}$ & 0.21 & $\pm 0.0^{\mathrm{b}}$ & 0.16 & $\pm 0.00^{b}$ & 3.86 & $\pm 0.03^{\mathrm{d}}$ & 0.16 & $\pm 0.02^{b}$ & 1.48 & $\pm 0.0^{\mathrm{c}}$ & 1.5 \\
\hline $\mathrm{Fe}$ & 3.12 & $\pm 0.1^{\mathrm{a}}$ & 0.22 & $\pm 0.0^{\mathrm{bd}}$ & 0.01 & $\pm 0.00^{\mathrm{d}}$ & 19.04 & $\pm 0.22 \mathrm{e}$ & 0.31 & $\pm 0.05^{\mathrm{b}}$ & 3.40 & $\pm 0.01^{\mathrm{c}}$ & 11.0 \\
\hline Mn & 0.75 & $\pm 0.1^{\mathrm{a}}$ & 0.07 & $\pm 0.0^{\mathrm{b}}$ & 0.01 & $\pm 0.00^{b}$ & 6.66 & $\pm 0.14^{\mathrm{e}}$ & & $.1^{\mathrm{b}}$ & 1.06 & $\pm 0.02^{c}$ & 3 \\
\hline $\begin{array}{c}\text { Se } \\
(\mu g / 100 g)\end{array}$ & 3628 & $\pm 51^{\mathrm{a}}$ & 15 & $\pm 0.2^{\mathrm{d}}$ & 8.3 & $\pm 0.14^{\mathrm{d}}$ & 537 & $\pm 6^{b}$ & 19 & $\pm 0.3^{\mathrm{d}}$ & 229 & $\pm 3^{c}$ & $\begin{array}{c}70 \\
(\mu \mathrm{g} / \text { day })\end{array}$ \\
\hline
\end{tabular}

${ }^{1}$ Expressed on fresh weight basis; ${ }^{2}$ Expressed on dry weight basis; ${ }^{3}$ DRV, Dietary reference value based in Population reference intakes and adequate intakes (PRI-AI) of minerals for adults (estimated for males and females $\geq 18$ years old), EFSA [67]; Data are expressed as means \pm SD $(n=3)$. The different superscript letters within a row are significantly different $(p<0.05)$.

With respect to beverages, as shown in Table 8, in most minerals, WBM had slightly higher concentrations than BM-S. This is understandable due to the participation of the sediment in the WBM, which has a high level of minerals. When compared with other commercial vegetable milks (from soybean, almond, rice, and coconut), reported by Vanga and Raghavan [68], the WBM showed, in most minerals, a level within the range, i.e., at $\mathrm{Mg}$ (13-49 mg/100 g f.w.), K (47-364 mg/100 g f.w.), P (48-108 mg/100 g f.w.), Fe (0.05-0.84 mg/100 $\mathrm{g} \mathrm{f.w),} \mathrm{and} \mathrm{Z} \mathrm{(0.38-0.75} \mathrm{mg/100} \mathrm{g} \mathrm{f.w.).} \mathrm{In} \mathrm{BM-S,} \mathrm{a} \mathrm{lower} \mathrm{mineral}$ 
content than commercial vegetable milks was noted. Regarding calcium, both WBM (13.9 mg/100 g f.w.) and BM-S (2.4 mg/100 g f.w.) had lower concentrations than other commercial plant milks, which typically have values greater to $100 \mathrm{mg} / 100 \mathrm{~mL}$ as they are often fortified to mimic the calcium content of cow's milk [68]. In the aspect of daily nutritional intake (DRV of Table 8), a cup ( $240 \mathrm{~mL}$ ) of WBM beverage may contribute mainly $\mathrm{Mg}$ with $26.5 \%$, P with $26.4 \%$, and $\mathrm{Cu}$ with $34 \%$. As for the BM-S beverage, only $\mathrm{Cu}$ with $26 \%$. The rest of the minerals had a contribution of less than $10 \%$ in both WBM and BM-S beverages.

Regarding by-products, it was observed (Table 8) that the BM-D had higher mineral concentrations $(p<0.05)$ than cake and BM-F. Regarding its daily nutritional contribution (according to DRV), an intake of $10 \mathrm{~g}$ d.w. of BM-D may to provide $\mathrm{P}$ with $84 \%, \mathrm{Mg}$ with $71 \%$, Zn with $32 \%$, Cu with $27 \%$, Mn with $22 \%$, Fe with $17 \%$, and Ca with $12 \%$. The cake, with an intake of $100 \mathrm{~g}$ d.w., may provide $\mathrm{Mg}$ with $160 \%$, P with $132 \%$, Cu with $102 \%$, Zn with $50 \%$, Mn with $36 \%$, Fe with $30 \%$, and Ca with $22 \%$. According to the above, BM-D and cake by-products represent an important source of $\mathrm{Mg}, \mathrm{P}, \mathrm{Zn}$, and $\mathrm{Cu}$ and $\mathrm{Mn}, \mathrm{Fe}$, and Ca to a lesser degree.

\subsection{Antioxidant Capacity}

In this work, three in vitro methods were used to evaluate the antioxidant capacity of the BN samples, as shown in Table 9. The antioxidant level of the Brazil nut showed consistency to the previous report, i.e., $2.6 \mu \mathrm{mol} \mathrm{TE} / \mathrm{g}$ f.w. by DPPH assay [20], $\sim 11 \mu \mathrm{mol}$ TE/g f.w. by TEAC, and $26 \mu \mathrm{mol}$ TE/g f.w. by ORAC [12].

Table 9. Antioxidant capacity of the Brazil nut (Bertholletia excelsa HBK), its beverages (WBM and BM-S), and by-products (BM-D and cake), expressed as $\mu \mathrm{mol} \mathrm{TE} / \mathrm{g}$.

\begin{tabular}{cccccccccccc}
\hline \multirow{2}{*}{ Assay } & \multicolumn{2}{c}{ Raw Material } & \multicolumn{4}{c}{ Beverages } & \multicolumn{4}{c}{ Byproducts } \\
\cline { 2 - 11 } & \multicolumn{2}{c}{ BN $^{\mathbf{1}}$} & \multicolumn{2}{c}{ WBM $^{\mathbf{1}}$} & \multicolumn{2}{c}{ BM-S $^{\mathbf{1}}$} & \multicolumn{3}{c}{ BM-D $^{\mathbf{2}}$} & \multicolumn{2}{c}{ Cake $^{\mathbf{2}}$} \\
\hline DPPH & 1.72 & $\pm 0.11^{\mathrm{a}}$ & 0.08 & $\pm 0.00^{\mathrm{b}}$ & 0.07 & $\pm 0.00^{\mathrm{b}}$ & 1.52 & $\pm 0.04^{\mathrm{c}}$ & 0.27 & $\pm 0.03^{\mathrm{d}}$ \\
TEAC & 14.39 & $\pm 0.46^{\mathrm{a}}$ & 0.82 & $\pm 0.04^{\mathrm{b}}$ & 0.71 & $\pm 0.03^{\mathrm{b}}$ & 11.03 & $\pm 0.89^{\mathrm{c}}$ & 3.34 & $\pm 0.15^{\mathrm{d}}$ \\
ORAC & 10.98 & $\pm 0.45^{\mathrm{a}}$ & 0.61 & $\pm 0.01^{\mathrm{b}}$ & 0.47 & $\pm 0.01^{\mathrm{b}}$ & 14.18 & $\pm 0.77^{\mathrm{c}}$ & 6.73 & $\pm 0.40^{\mathrm{d}}$ \\
\hline
\end{tabular}

$\overline{{ }^{1} \text { Expressed on fresh weight basis; }{ }^{2} \text { Expressed on dry weight basis. Data are expressed as means } \pm \mathrm{SD}(n=3)}$. The different superscript letters within a row are significantly different $(p<0.05)$.

Regarding the BN beverages, WBM and BM-S showed a similar antioxidant capacity, with no significant difference $(p<0.05)$. In the DPPH assay, WBM and BM-S had 8 and $7 \mu \mathrm{mol} \mathrm{TE} / 100 \mathrm{~g}$ f.w., respectively, values that are in the range of other commercial vegetable milks that range from $4.7-30.5 \mu \mathrm{mol}$ TE/100 $\mathrm{mL}$ by DPPH [28].

With respect to the antioxidant capacity of the BN by-products (Table 9), the BM-D showed greater antioxidant power than the cake. These results had a relationship with the TPC content shown in Table 2. In the literature, there are no reports about the antioxidant capacity of the cake obtained as a by-product of beverage processing of $\mathrm{BNs}$, but our result is similar to the cake obtained from defatted BNs by pressing $(4.07 \mu \mathrm{mol}$ TE/g d.w. by TEAC assay), reported by Gomes [30]. If compared to the antioxidant power (by TEAC assay) of the cake produced by soymilk (called "okara"), with 19-29 $\mu \mathrm{mol} \mathrm{TE/g} \mathrm{d.w.} \mathrm{[69],}$ the antioxidant capacity of the BN cake was minimal.

\section{Conclusions}

The present study reports a comprehensive compositional characterization of the Brazil nut (BN), its derived beverages, and processing by-products. The BN showed an interesting nutritional quality related to its bioactive constituents (such as unsaturated fatty acids, phytosterols, tocopherols, squalene, phenolic compounds, proteins, and selenium). Twenty-four phenolic compounds were identified in Brazil nuts and products, flavan-3ols and the hydroxybenzoic acids, the phenolics more abundant. Brazil nut beverages showed an interesting content in phenolic compounds, and their nutritional value was 
comparable to other commercialized vegetable milks, WBM being the beverage with the higher content of nutritional components as the minor bioactive lipids (total tocopherols, $\beta$-sitosterol, and squalene). The selenium content of the Brazil nut beverage was higher than those reported for other commercial vegetable milks. For this reason, the BN beverage represented an important alternative source to the daily requirement of Se in the human diet. Additionally, the hydrothermal processing for beverage production has a significant effect on the content of some minor lipid components (FFA, MG, total tocopherol, $\beta$-sitosterol, and squalene), by the hydrolysis of triglycerides and certain conjugated compounds. Regarding the $\mathrm{BN}$ by-products, the fat fraction (BM-F) is mainly composed of oleic and linoleic acids and other minor lipid components; the sediment fraction, a by-product produced in minimal quantities, showed high content of protein, selenium, other minerals, and phenolic compounds; and the cake retained many of the nutritional components of the BNs. The present study provides some support for future studies related to the improvement of the technological processes used to produce BN beverages, to influence the stability of these processes (physical and oxidative) regarding bioactive compounds present in the beverage, as well as the development of a smart formulation of $\mathrm{BN}$ beverages according to the target consumer (older people, children, others).

Supplementary Materials: The following are available online at https:/ /www.mdpi.com/article/ 10.3390/foods10123007/s1, Figure S1: Calibration curves of the standard phenolic compounds (catechin, epicatechin, quercetin and rutin), Figure S2: Calibration curves of the standard phenolic compounds (gallic acid, 4-hidroxy benzoic acid, vanillic acid, p-coumaric acid, ferulic acid and ellagic acid) for HPLC quantitation.

Author Contributions: Conceptualization, M.P.C. and T.F.; methodology, W.V.V.-R., M.P.C., D.M. and B.M.; software, W.V.V.-R.; validation, W.V.V.-R., M.P.C., D.M. and B.M.; formal analysis, W.V.V.-R., D.M. and B.M.; investigation, W.V.V.-R., M.P.C., T.F. and I.R.; resources, M.P.C.; data curation, M.P.C., T.F., I.R. and W.V.V.-R.; writing—original draft preparation, W.V.V.-R., D.M. and B.M.; writingreview and editing, M.P.C., T.F. and I.R.; visualization, M.P.C. and T.F.; supervision, M.P.C., T.F. and I.R.; project administration, M.P.C.; funding acquisition, M.P.C. All authors have read and agreed to the published version of the manuscript.

Funding: This research was funded by the Spanish Ministry of Science and Innovation, project number RTA2015-00044-C02-02 and PID2020-118300RB-C21.

Institutional Review Board Statement: Not applicable.

Informed Consent Statement: Not applicable.

Data Availability Statement: Data is contained within the article.

Acknowledgments: Author Wilson V. Vasquez thanks the scholarship "Presidente de la Republica" postgrade program (RJ 4285-2018/MINEDU/VMGI-PRONABEC-OBE) from the Ministry of Education of the Republic of Peru.

Conflicts of Interest: The authors declare that there is no conflict of interest regarding the publication of this paper.

\section{References}

1. Kainer, K.A.; Wadt, L.H.O.; Staudhammer, C.L. The evolving role of Bertholletia excelsa in Amazonia: Contributing to local livelihoods and forest conservation. Desenvolv. Meio Ambient. 2018, 48, 477-497. [CrossRef]

2. Eslami, O.; Shidfar, F.; Dehnad, A. Inverse association of long-term nut consumption with weight gain and risk of overweight/obesity: A systematic review. Nutr. Res. 2019, 68, 1-8. [CrossRef] [PubMed]

3. Cardoso, B.R.; Duarte, G.B.S.; Reis, B.Z.; Cozzolino, S.M.F. Brazil nuts: Nutritional composition, health benefits and safety aspects. Food Res. Int. 2017, 100, 9-18. [CrossRef]

4. Chalupa-Krebzdak, S.; Long, C.J.; Bohrer, B.M. Nutrient density and nutritional value of milk and plant-based milk alternatives. Int. Dairy J. 2018, 87, 84-92. [CrossRef]

5. Aydar, E.F.; Tutuncu, S.; Ozcelik, B. Plant-based milk substitutes: Bioactive compounds, conventional and novel processes, bioavailability studies, and health effects. J. Funct. Foods 2020, 70, 103975. [CrossRef] 
6. Felberg, I.; Antoniassi, R.; Deliza, R.; de Freitas, S.C.; Modesta, R.C. Della Bebida de soja e castanha do Brasil: Processamento, composição, avaliação sensorial e de cor. Cienc. Tecnol. Aliment. 2009, 29, 609-617. [CrossRef]

7. Cardarelli, H.R.; Joaquim, A. Conservation of Brazil Nut extract. Sci. Agric. 2000, 57, 617-622. [CrossRef]

8. Kluczkovski, A.; Lima, N.; Oliveira, M.K. Brazil nut powdered milk properties. J. Food Process. Preserv. 2017, 41, 1-6. [CrossRef]

9. Sartori, A.G.D.O.; Machado, M.C.; Bastos, D.H.M.; de Alencar, S.M.; Regitano-d'Arce, M.A.B. Water-extracted Brazil nut coproducts: Nutritional value and estimation of nutrient losses during processing. J. Food Meas. Charact. 2020, 14, 1919-1925. [CrossRef]

10. Association of Official Analytical Chemists (AOAC). Official Method of Analysis, 18th ed.; AOAC International: Washington, DC, USA, 2005; ISBN 9780935584424.

11. Folch, J.; Lees, M.; Sloane Stanley, G.H. A simple technique to rule out occlusion of right coronary artery after aortic valve surgery. J. Biol. Chem. 1956, 226, 497-509. [CrossRef]

12. John, J.A.; Shahidi, F. Phenolic compounds and antioxidant activity of Brazil nut (Bertholletia excelsa). J. Funct. Foods 2010, 2, 196-209. [CrossRef]

13. Cano, M.P.; Gómez-Maqueo, A.; García-Cayuela, T.; Welti-Chanes, J. Characterization of carotenoid profile of Spanish Sanguinos and Verdal prickly pear (Opuntia ficus-indica, spp.) tissues. Food Chem. 2017, 237, 612-622. [CrossRef] [PubMed]

14. García-Cayuela, T.; Gómez-Maqueo, A.; Guajardo-Flores, D.; Welti-Chanes, J.; Cano, M.P. Characterization and quantification of individual betalain and phenolic compounds in Mexican and Spanish prickly pear (Opuntia ficus-indica L. Mill) tissues: A comparative study. J. Food Compos. Anal. 2019, 76, 1-13. [CrossRef]

15. Herrera, T.; Navarro del Hierro, J.; Fornari, T.; Reglero, G.; Martin, D. Acid hydrolysis of saponin-rich extracts of quinoa, lentil, fenugreek and soybean to yield sapogenin-rich extracts and other bioactive compounds. J. Sci. Food Agric. 2019, 99, $3157-3167$. [CrossRef]

16. Sanchón, J.; Fernández-Tomé, S.; Miralles, B.; Hernández-Ledesma, B.; Tomé, D.; Gaudichon, C.; Recio, I. Protein degradation and peptide release from milk proteins in human jejunum. Comparison with in vitro gastrointestinal simulation. Food Chem. 2018, 239, 486-494. [CrossRef] [PubMed]

17. Miralles, B.; Sanchón, J.; Sánchez-Rivera, L.; Martínez-Maqueda, D.; Le Gouar, Y.; Dupont, D.; Amigo, L.; Recio, I. Digestion of micellar casein in duodenum cannulated pigs. Correlation between in vitro simulated gastric digestion and in vivo data. Food Chem. 2021, 343, 128424. [CrossRef] [PubMed]

18. López-Bellido, F.J.; Sanchez, V.; Rivas, I.; López-Bellido, R.J.; López-Bellido, L. Wheat grain selenium content as affected by year and tillage system in a rainfed Mediterranean Vertisol. F. Crop. Res. 2019, 233, 41-48. [CrossRef]

19. Nielsen, S.S. Food Analysis, 5th ed.; Springer Nature: West Lafayette, IN, USA, 2017; ISBN 9783319457741.

20. Abe, L.T.; Lajolo, F.M.; Genovese, M.I. Comparison of phenol content and antioxidant capacity of nuts. Ciênc. Tecnol. Aliment. 2010, 30, 254-259. [CrossRef]

21. Koroleva, O.; Torkova, A.; Nikolaev, I.; Khrameeva, E.; Fedorova, T.; Tsentalovich, M.; Amarowicz, R. Evaluation of the antiradical properties of phenolic acids. Int. J. Mol. Sci. 2014, 15, 16351-16380. [CrossRef]

22. Gómez-Maqueo, A.; García-Cayuela, T.; Welti-Chanes, J.; Cano, M.P. Enhancement of anti-inflammatory and antioxidant activities of prickly pear fruits by high hydrostatic pressure: A chemical and microstructural approach. Innov. Food Sci. Emerg. Technol. 2019, 54, 132-142. [CrossRef]

23. Silva, A.R.A.; Silva, M.M.N.; Ribeiro, B.D. Health issues and technological aspects of plant-based alternative milk. Food Res. Int. 2020, 131, 108972. [CrossRef]

24. McClements, D.J.; Newman, E.; McClements, I.F. Plant-based Milks: A Review of the Science Underpinning Their Design, Fabrication, and Performance. Compr. Rev. Food Sci. Food Saf. 2019, 18, 2047-2067. [CrossRef]

25. Shimoyamada, M.; Tsushima, N.; Tsuzuki, K.; Asao, H.; Yamauchi, R. Effect of Heat Treatment on Dispersion Stability of Soymilk and Heat Denaturation of Soymilk Protein. Food Sci. Technol. Res. 2008, 14, 32-38. [CrossRef]

26. Devnani, B.; Ong, L.; Kentish, S.; Gras, S. Heat induced denaturation, aggregation and gelation of almond proteins in skim and full fat almond milk. Food Chem. 2020, 325, 126901. [CrossRef]

27. Santos, O.V.; Corrêa, N.C.F.; Carvalho, R.N.; Costa, C.E.F.; França, L.F.F.; Lannes, S.C.S. Comparative parameters of the nutritional contribution and functional claims of Brazil nut kernels, oil and defatted cake. Food Res. Int. 2013, 51, 841-847. [CrossRef]

28. Silva, J.G.S.; Rebellato, A.P.; Caramês, E.T. dos S.; Greiner, R.; Pallone, J.A.L. In vitro digestion effect on mineral bioaccessibility and antioxidant bioactive compounds of plant-based beverages. Food Res. Int. 2020, 130, 108993. [CrossRef]

29. Manzoor, M.F.; Zeng, X.A.; Ahmad, N.; Ahmed, Z.; Rehman, A.; Aadil, R.M.; Roobab, U.; Siddique, R.; Rahaman, A. Effect of pulsed electric field and thermal treatments on the bioactive compounds, enzymes, microbial, and physical stability of almond milk during storage. J. Food Process. Preserv. 2020, 44, 1-14. [CrossRef]

30. Gomes, S.; Torres, A.G. Optimized extraction of polyphenolic antioxidant compounds from Brazil nut (Bertholletia excelsa) cake and evaluation of the polyphenol profile by HPLC. J. Sci. Food Agric. 2015, 96, 2805-2814. [CrossRef]

31. Chen, P.C.; Lin, C.; Chen, M.H.; Chiang, P.Y. The micronization process for improving the dietary value of okara (soybean residue) by planetary ball milling. LWT 2020, 132, 109848. [CrossRef]

32. Lazarin, R.A.; Falcão, H.G.; Ida, E.I.; Berteli, M.N.; Kurozawa, L.E. Rotating-Pulsed Fluidized Bed Drying of Okara: Evaluation of Process Kinetic and Nutritive Properties of Dried Product. Food Bioprocess Technol. 2020, 13, 1611-1620. [CrossRef] 
33. Miraliakbari, H.; Shahidi, F. Antioxidant activity of minor components of tree nut oils. Food Chem. 2008, 111, 421-427. [CrossRef] [PubMed]

34. Spínola, V.; Pinto, J.; Castilho, P.C. Identification and quantification of phenolic compounds of selected fruits from Madeira Island by HPLC-DAD-ESI-MSn and screening for their antioxidant activity. Food Chem. 2015, 173, 14-30. [CrossRef] [PubMed]

35. Mata, A.; Ferreira, J.P.; Semedo, C.; Serra, T.; Duarte, C.M.M.; Bronze, M.R. Contribution to the characterization of Opuntia spp. juices by LC-DAD-ESI-MS/MS. Food Chem. 2016, 210, 558-565. [CrossRef]

36. Bylund, D.; Norström, S.H.; Essén, S.A.; Lundström, U.S. Analysis of low molecular mass organic acids in natural waters by ion exclusion chromatography tandem mass spectrometry. J. Chromatogr. A 2007, 1176, 89-93. [CrossRef] [PubMed]

37. Arráez-Román, D.; Fu, S.; Sawalha, S.M.S.; Segura-Carretero, A.; Fernández-Gutiérrez, A. HPLC/CE-ESI-TOF-MS methods for the characterization of polyphenols in almond-skin extracts. Electrophoresis 2010, 31, 2289-2296. [CrossRef]

38. Milbury, P.E.; Chen, C.Y.; Dolnikowski, G.G.; Blumberg, J.B. Determination of flavonoids and phenolics and their distribution in almonds. J. Agric. Food Chem. 2006, 54, 5027-5033. [CrossRef]

39. Pycia, K.; Kapusta, I.; Jaworska, G.; Jankowska, A. Antioxidant properties, profile of polyphenolic compounds and tocopherol content in various walnut (Juglans regia L.) varieties. Eur. Food Res. Technol. 2019, 245, 607-616. [CrossRef]

40. Bueno-Herrera, M.; Pérez-Magariño, S. Validation of an extraction method for the quantification of soluble free and insoluble bound phenolic compounds in wheat by HPLC-DAD. J. Cereal Sci. 2020, 93, 102984. [CrossRef]

41. Jaiswal, R.; Jayasinghe, L.; Kuhnert, N. Identification and characterization of proanthocyanidins of 16 members of the Rhododendron genus (Ericaceae) by tandem LC-MS. J. Mass Spectrom. 2012, 47, 502-515. [CrossRef]

42. Ojeda-Amador, R.M.; Salvador, M.D.; Fregapane, G.; Gómez-Alonso, S. Comprehensive Study of the Phenolic Compound Profile and Antioxidant Activity of Eight Pistachio Cultivars and Their Residual Cakes and Virgin Oils. J. Agric. Food Chem. 2019, 67, 3583-3594. [CrossRef]

43. Zhao, Y.; Chen, P.; Lin, L.; Harnly, J.M.; Yu, L.; Li, Z. Tentative identification, quantitation, and principal component analysis of green pu-erh, green, and white teas using UPLC/DAD/MS. Food Chem. 2011, 126, 1269-1277. [CrossRef] [PubMed]

44. Regueiro, J.; Sánchez-gonzález, C.; Vallverdú-queralt, A.; Simal-gándara, J.; Lamuela-raventós, R.; Izquierdo-pulido, M. Comprehensive identification of walnut polyphenols by liquid chromatography coupled to linear ion trap-Orbitrap mass spectrometry. Food Chem. 2014, 152, 340-348. [CrossRef] [PubMed]

45. Slatnar, A.; Mikulic-petkovsek, M.; Stampar, F.; Veberic, R.; Solar, A. HPLC-MS n identi fi cation and quanti fi cation of phenolic compounds in hazelnut kernels, oil and bagasse pellets. Food Res. Int. 2014, 64, 783-789. [CrossRef]

46. Bodoira, R.; Maestri, D. Phenolic Compounds from Nuts: Extraction, Chemical Profiles, and Bioactivity. J. Agric. Food Chem. 2020, 68, 927-942. [CrossRef]

47. Bhagwat, S.; Haytowitz, D.B. USDA Database for the Flavonoid Content of Selected Foods. Release 3.2; USDA NAL: Maryland, MD, USA, 2015.

48. Özcan, M.M.; Al Juhaimi, F.; Uslu, N. The effect of heat treatment on phenolic compounds and fatty acid composition of Brazilian nut and hazelnut. J. Food Sci. Technol. 2018, 55, 376-380. [CrossRef]

49. Xu, B.; Chang, S.K.C. Isoflavones, flavan-3-ols, phenolic acids, total phenolic profiles, and antioxidant capacities of soy milk as affected by ultrahigh-temperature and traditional processing methods. J. Agric. Food Chem. 2009, 57, 4706-4717. [CrossRef]

50. Favari, C.; Mena, P.; Curti, C.; Del, D. Flavan-3-ols: Catechins and Proanthocyanidins. In Dietary Polyphenols: Metabolism and Health Effect; Tomás-Barberán, F.A., González-Sarrías, A., García-Villalba, R., Eds.; John Wiley \& Sons, Inc.: Chennai, India, 2021; pp. 283-317. ISBN 9781119563716.

51. Kumar, N.; Goel, N. Phenolic acids: Natural versatile molecules with promising therapeutic applications. Biotechnol. Rep. 2019, 24, 1-10. [CrossRef] [PubMed]

52. Calder, P.C. Functional Roles of Fatty Acids and Their Effects on Human Health. J. Parenter. Enter. Nutr. 2015, 39, 18S-32S. [CrossRef] [PubMed]

53. Weston, M.; Kuchel, R.P.; Chandrawati, R. A Polydiacetylene-Based Colorimetric Sensor as an Active Use-By Date for Plant-Based Milk Alternatives. Macromol. Rapid Commun. 2020, 41, 2000172. [CrossRef]

54. Santos, O.V.; Corrêa, N.C.F.; Soares, F.A.S.M.; Gioielli, L.A.; Costa, C.E.F.; Lannes, S.C.S. Chemical evaluation and thermal behavior of Brazil nut oil obtained by different extraction processes. Food Res. Int. 2012, 47, 253-258. [CrossRef]

55. Union Europea. Regulation (EU) No 1308/2013. Establishing a Common Organisation of the Markets in Agricultural Products. Available online: https:/ / eur-lex.europa.eu (accessed on 12 March 2020).

56. Kundu, P.; Dhankhar, J.; Sharma, A. Development of Non Dairy Milk Alternative Using Soymilk and Almond Milk. Curr. Res. Nutr. Food Sci. 2018, 06, 203-210. [CrossRef]

57. Shahidi, F.; Camargo, A.C. De Tocopherols and Tocotrienols in Common and Emerging Dietary Sources: Occurrence, Applications, and Health Benefits. Int. J. Mol. Sci. 2016, 17, 1745. [CrossRef] [PubMed]

58. Derewiaka, D.; Szwed, E.; Wołosiak, R. Physicochemical properties and composition of lipid fraction of selected edible nuts. Pak. J. Bot. 2014, 46, 337-343.

59. Lozano-Grande, M.A.; Gorinstein, S.; Espitia-Rangel, E.; Dávila-Ortiz, G.; Martínez-Ayala, A.L. Plant Sources, Extraction Methods, and Uses of Squalene. Int. J. Agron. 2018, 2018, 2-14. [CrossRef] 
60. Vasquez, W.V.; Hernández, D.M.; del Hierro, J.N.; Martin, D.; Cano, M.P.; Fornari, T. Supercritical carbon dioxide extraction of oil and minor lipid compounds of cake byproduct from Brazil nut (Bertholletia excelsa) beverage production. J. Supercrit. Fluids 2021, 171, 105188. [CrossRef]

61. Sharma, G.M.; Mundoma, C.; Seavy, M.; Roux, K.H.; Sathe, S.K. Purification and Biochemical Characterization of Brazil nut (Bertholletia excelsa L.) Seed Storage Proteins. J. Agric. Food Chem. 2010, 58, 5714-5723. [CrossRef]

62. Sathe, S.K.; Venkatachalam, M.; Sharma, G.M.; Kshirsagar, H.H.; Teuber, S.S.; Roux, K.H. Solubilization and Electrophoretic Characterization of Select Edible Nut Seed Proteins. J. Agric. Food Chem. 2009, 57, 7846-7856. [CrossRef] [PubMed]

63. Ampe, C.; Van Damme, J.; de Castro, L.A.B.; Sampaio, M.J.A.M.; Van Montagu, M.; Vandekerckhove, J. The amino-acid sequence of the 2S sulphur-rich proteins from seeds of Brazil nut (Bertholletia excelsa H.B.K.). Eur. J. Biochem. 1986, 159, 597-601. [CrossRef]

64. Lima, L.W.; Stonehouse, G.C.; Walters, C.; El Mehdawi, A.F.; Fakra, S.C.; Pilon-Smits, E.A.H. Selenium accumulation, speciation and localization in Brazil nuts (Bertholletia excelsa H.B.K.). Plants 2019, 8, 289. [CrossRef] [PubMed]

65. Departamento de Agricultura de los Estados Unidos (USDA) USDA National Nutrient Database for Standard Reference, Release 28. Available online: https://ndb.nal.usda.gov/ndb/ (accessed on 10 January 2020).

66. Jayasinghe, S.B.; Caruso, J.A. Investigation of Se-containing proteins in Bertholletia excelsa H.B.K. (Brazil nuts) by ICPMS, MALDI-MS and LC-ESI-MS methods. Int. J. Mass Spectrom. 2011, 307, 16-27. [CrossRef]

67. European Food Safety Authority (EFSA). Dietary Reference Values for nutrients Summary report. EFSA Support. Publ. 2017, 14, 1-98. [CrossRef]

68. Vanga, S.K.; Raghavan, V. How well do plant based alternatives fare nutritionally compared to cow's milk? J. Food Sci. Technol. 2018, 55, 10-20. [CrossRef] [PubMed]

69. Stanojevic, S.P.; Barac, M.B.; Pesic, M.B.; Zilic, S.M.; Kresovic, M.M.; Vucelic-Radovic, B.V. Mineral elements, lipoxygenase activity, and antioxidant capacity of okara as a byproduct in hydrothermal processing of soy milk. J. Agric. Food Chem. 2014, 62, 9017-9023. [CrossRef] [PubMed] 